\title{
Private Investment and Public Equity Returns
}

\author{
Robert Couch and Wei $\mathrm{Wu}^{*}$
}

March 31, 2012

*Atkinson Graduate School of Management, Willamette University, 900 State Street, Salem, OR 97301, USA. Email: rcouch@willamette.edu and wwu@willamette.edu. Tel: 503-370-6227. Fax: 503-3703011. We would like to thank Michael Gallmeyer, Rick Green, Burton Hollifield, Xiaoqing Hu, Norman Schuerhoff, and Zhiguang Wang for helpful comments. 


\begin{abstract}
Because of external financing costs, private business owners often need to self-finance new investment projects. These self-financing needs create an incentive for business owners to hold financial assets whose payoffs are positively correlated with self-financing needs. If this effect is aggregated, expected returns on financial assets should be negatively correlated with aggregate private investment self-financing needs. To test the cross-sectional asset pricing implications of this conjecture, we use realized noncorporate investment growth and future forecasted noncorporate investment growth as proxies for self-financing needs. We find that our private investment model can explain a good share of the cross-sectional returns of size-, value- and distress-sorted equity portfolios, almost as well as the Fama-French factors. In contrast to the Fama-French model, however, we find the signs on our estimated coefficients to be consistent with our theoretical predictions.
\end{abstract}

Keywords: Asset pricing, financial constraints, private investment, GMM

JEL Classification: G12 


\section{Introduction}

The effect of the private business sector on the prices of public-traded stocks has received only scant attention in the finance literature. The most notable study is Heaton and Lucas (2000) who find that including aggregate private business profits in Jaganathan and Wang's (1996) labor-enhanced conditional CAPM can help explain the cross-section of size and value portfolio returns. Heaton and Lucas find that stocks which have positive correlation with aggregate private business income trade at a discount, and thus have higher average returns, relative to stocks that have low or negative correlation with aggregate private business income. This is in accordance with their prediction based on income-diversification incentives that background income risk commands a positive risk premium. However, when we test a version of the Heaton-Lucas model using an updated time horizon and a different set of test assets which includes distress-sorted portfolios, we find that labor income and proprietary business income are traded at a premium instead of a discount. One of the main purposes of this paper is to propose and test a theoretical framework in which this result can be related to a rational, economic incentive.

Rather than starting from traditional diversification theory, we consider the hedging incentives that financially-constrained private business owners face. If private business owners face external financing costs, they will have an incentive to inject money from their personal financial savings into their private business in order to either expand via new investment projects during up-cycles or to prevent inefficient downsizing during down-cycles. The private investment self-financing needs at work here are analogous to the hedging incentives analyzed by Froot, Scharfstein and Stein (1993) who show that, in the presence of external financing costs, assets whose returns are correlated with investment opportunities make good hedging instruments. The implication of this result, applied to private business owners, is that assets whose returns have high correlation with self-financing needs should face higher demand by private business owners than assets whose returns have low correlation 
with self-financing needs. In aggregate, this extra demand implies that financial assets whose returns have high correlation with private investment self-financing needs should, all else equal, trade at a premium and thus exhibit lower average returns.

Testing this conjecture would be straightforward if self-financing needs were directly observable. Since this is not the case, we infer self-financing needs using forecasted and realized noncorporate investment growth. These variables are used in order to approximate self-financing needs for, respectively, planned and contemporaneous private investment. We use forecasted noncorporate investment as a proxy for planned investment since there is typically a delay between the preliminary financing stages of investment planning and the actual implementation and reporting of investment projects. Realized noncorporate investment, on the other hand, captures self-financing needs associated with contemporaneously-realized investment projects.

For test assets, we use the 25 Fama-French size- and value-sorted portfolios plus 10 distress-sorted portfolios following Campbell, Hilscher and Szilagyi (2008). Using FamaMacbeth and generalized method of moment estimation procedures, we find that our model is able to explain the cross-section of expected returns about as good as the Fama-French size and value factors. More importantly, whereas the estimated sign on key risk premium coefficients is puzzling in the Fama-French specification, and other specifications, the sign on our risk premium coefficients is consistent with our private investment explanation. For example, the estimated coefficient for market returns in the Fama-French model using our test assets is significantly negative. This is in accordance with the findings in Campbell, Hilscher and Szilagyi (2008) who show that market beta is significantly related to their distress portfolios, but with higher betas corresponding to the more distressed portfolios which have lower average returns. Although this is puzzling from a traditional portfoliodiversification perspective, this is not surprising from the perspective of our private investment approach: positive market returns are an indicator of greater investment opportunities 
and self-financing needs, and since private business owners have an incentive to hedge these needs, the risk premium on market returns is negative.

We also analyze the effect of time-varying credit conditions. In credit crunch periods, we find statistical evidence of investment-cash flow sensitivity in the noncorporate business sector, consistent with the hypothesis of Fazzari, Hubbard and Petersen (1988) who argue that invest-cash flow sensitivity is evidence of costly external financing. We also find evidence that suggests self-financing needs are more associated with investment plans during a credit boom, and more associated with contemporaneous investment projects in a credit crunch. That is, in periods where the credit spread is below its mean (a credit boom), we find that expected future noncorporate investment growth has a stronger effect on asset prices than when the credit spread is above its mean (a credit crunch). This is consistent with idea that business conditions and next-quarter investment opportunities are better in a credit boom than in a credit crunch. On the other hand, in periods where the credit spread is above its mean, we find that contemporaneous noncorporate investment growth has a stronger effect on asset prices than when the credit spread is below its mean. This is consistent with the idea that during a credit crunch there is reduced investment planning activity and a greater need for supplemental self-financing of projects in the latter stages of implementation.

In related investment-based cross-sectional asset pricing work, Cochrane (1996) and Li, Vassalou and Xing (2006) show that size and value premia can largely be explained by sectoral investment factors. These models, however, are motivated by macroeconomic models with multisector total factor productivity shocks and a linear pricing kernel specification relative to sectoral investment returns or growth rates. In contrast, we focus on the private investment sector, motivated by financial frictions associated with the private business sector. Another investment-based study is by Gomes, Yaron and Zhang (2003) who show that corporate financing frictions can help explain the cross-section of expected returns. 
However, whereas Gomes et al. use corporate measures of investment and financial constraints and focus only on size-sorted portfolios, we focus on noncorporate measures and we are able to explain size-, value- and distress-sorted portfolios. Two other studies consider financial constraints from a corporate rather than noncorporate perspective. Lamont, Polk and Saa-Requejo (2001) study a cross-section of financially constrained firms, as defined by the Kaplan and Zingales (1997) index, and find that financially constrained firms have lower expected returns. However, Whited and Wu (2006) construct a different measure of corporate financial constraints and find the opposite result, namely that financial constraints lead to higher expected returns.

Petkova and Zhang (2005) use macroeconomic variables to predict future investment conditions and document a positive relationship between market betas for value portfolios and the expected market risk premium. Although the direction of the relationship found by Petkova and Zhang is consistent with conditional CAPM theory, Lewellen and Nagel (2006) show that the empirical variation in the expected market risk premium is too small to explain the magnitude of the observed value premium. In contrast to the conditional CAPM framework of Petkova and Zhang, forecasting variables in our private investment model are not used to predict changes in the expected market risk premium; rather, forecasting variables in our model capture expected future private investment self-financing needs. Thus, the Lewellen-Nagel critique does not apply in our framework. We also differ from Petkova and Zhang in that we include distress-sorted portfolios as test assets.

In a recent working paper, Chen, Novy-Marx, and Zhang (2011) consider a 3-factor model based on market returns, a return-on-equity factor (high-profit firms minus low-profit firms), and an investment factor (low-investment firms minus high-investment firms). Their model is motivated by the "mechanical" valuation theory discussed in Fama and French (2006) and the $q$-theory of Liu, Whited and Zhang (2009). Although these theoretical motivation are distinct from our approach, we test their model relative to ours, and vice- 
versa, and find that our models add statistically significant explanatory power to each other. $^{1}$

In section 2 of the paper we discuss another strand of literature that documents the existence and source of costly external financing for private business owners. These costs arise from direct transaction costs as well as indirect costs associated with adverse selection and agency problems that are particularly significant with externally-financed private business ventures. $^{2}$ In section 2 we also provide theoretical motivation for our empirical specification. Then, in section 3 we explicate our estimation strategy. In section 4 we present the results of our private investment asset pricing regressions and compare our results to other benchmark models. In section 5 we present a bootstrap analysis of our empirical results. We conclude in section 6 .

\section{Motivation}

\subsection{Empirical Motivation}

Three main empirical findings motivate this study: (1) private business owners hold a significant portion of publicly-traded equity; (2) private business ownership significantly affects financial investment behavior; (3) many private business owners are financially constrained.

Regarding the first claim about the significance of private business owner equity ownership, Survey of Consumer Finances (SCF) data indicate that private business owners hold over a third of corporate equity in the household sector, ${ }^{3}$ and Flow of Funds data indicate

\footnotetext{
${ }^{1}$ We thank Chen, Novy-Marx, and Zhang for sharing their investment factor data with us.

${ }^{2}$ For an overview of the theory associated with costly external financing, see Stein (2003).

${ }^{3}$ Because total corporate equity holdings are not reported in the SCF, this estimate ranges from $45 \%$ if only directly held stocks are counted in 1998 SCF data, to $35 \%$ if estimates of corporate equity in mutual funds, pension funds, and IRAs are included, to 33\% using 1992 SCF data as reported in Heaton and Lucas (2000). Heaton and Lucas are interested in the motive to diversify proprietary income risk, and hence do
} 
that the household sector owns over $80 \%$ of total U.S. corporate equity. ${ }^{4}$ Data from the 1998 SCF indicate that only $9 \%$ of the population are private business owners, but private business owners are disproportionately wealthy and save more than non-business owners, as has been well documented. ${ }^{5}$ These estimates should be understood as representing a conservative estimate of the effects of private business ownership on stockholding for the following reasons: these data do not include prospective private business owners whose stockholdings are also likely to be influenced by private investment opportunities and financial constraints; there are a significant number of liquidity-constrained investors who do not fit the normal stereotype of private business owners, like private equity, venture capital, and hedge fund investors, who face similar financing needs that are closely related to our measures of private investment self-financing needs; SCF data over-samples wealthy households, but is still likely to underrepresent extremely wealthy private business owners, a class that likely has enormous influence on asset prices.

Regarding the second claim about the effect of private business ownership on savings behavior, there have been empirical studies that document how private business owners have different financial savings behavior than non-business owners. Studying exactly how private business affects the composition of financial portfolios is challenging, because of data limitations, but Heaton and Lucas (2000) and Cocco (2005) find that private business ownership decreases the proportion of corporate equity holdings relative to safer assets in households' financial portfolios. Gentry and Hubbard (2004) show that private business owners have higher savings rates than non-business owners, consistent with their predic-

not count as private business owners households with private business holdings less than $\$ 10,000$. Because we are interested in private investment opportunities, we classify a household as a private business owner if they have any non-zero amount of private business assets. Consequently, our estimate of private investment corporate equity holdings is higher than what Heaton and Lucas find.

${ }^{4}$ This estimate is obtained using table L.213, 1999 data, by adding direct household sector holdings, private pension funds, and private trusts and estates.

${ }^{5}$ See Gentry and Hubbard (2004). 
tion that external financing constraints lead private business owners to accumulate greater financial assets to finance future investment. Also, private business owners hold more corporate stock directly (as opposed to indirectly through, for example, retirement plans) than non-business owners, suggesting that private business owners are likely to be more active in choosing their stock portfolios according to their specific needs.

Regarding the third claim, an overview of the extent empirical evidence for financial constraints among entrepreneurs can be found in Kerr and Nanda (2009) and Kerr and Nanda (2011). Some highlights of this literature include Holtz-Eakin, Joulfaian and Rosen (1994b) who find indirect evidence that private business owners are financially constrained by showing how a sudden increase in wealth from an inheritance increases private business survivorship and profitability. Similarly, Holtz-Eakin, Joulfaian and Rosen (1994a) show that inheritance increases the probability of becoming an entrepreneur suggesting that potential as well as actual private business owners are affected by financial constraints.

In addition to financial constraints and self-financing needs faced by private business owners, we think that our factors of noncorporate investment growth and expected noncorporate investment growth proxy for other, noncorporate hedging demands that are highly correlated with the noncorporate sector. In this sense, our paper can be linked to other studies that study the propagating effects of financial constraints on macroeconomic activity. $^{6}$

\subsection{Theoretical Motivation}

Froot, Scharfstein and Stein (1993) show that the presence of external financing costs and future investment opportunities leads to hedging motives. Although they are primarily interested in hedging motives for corporations and optimal risk management policy, their

\footnotetext{
${ }^{6}$ See, for example, Cagetti and Nardi (2006), Clementi and Hopenhayn (2006), and Eisfeldt and Rampini (2007), and the literature reviews therein.
} 
results can be straightforwardly applied to private business owners. ${ }^{7}$ The main result in Froot et al. implies that private business owners will have a greater demand for financial assets whose payoffs are positively correlated with private investment self-financing needs. In an aggregate equilibrium setting, these hedging motives will lead to an increase in demand and lower expected return for assets whose returns are correlated with private investment self-financing needs.

To test for the presence of a private investment factor, we hypothesize that publiclytraded stock returns are a linear function of private investment self-financing needs. These self-financing needs account for changes in investment opportunities, business revenue (and hence liquidity needs), and credit conditions. Formally, we consider a linear asset pricing model such that

$$
\begin{aligned}
r_{n, t} & =\alpha_{n}+\beta_{n} \theta_{t}+\varepsilon_{n, t}, \\
E\left[\varepsilon_{n, t}\right] & =0, \text { and } \operatorname{Cov}\left(\theta_{t}, \varepsilon_{n, t}\right)=0,
\end{aligned}
$$

where $\theta_{t}$ represents private investment self-financing needs, $r_{n, t}$ represents the excess return (net of the riskless rate) on financial asset $n$ at time period $t$, and $\beta_{n}$ is a measure of the expected risk exposure of asset $n$ with the factor $\theta_{t}$. Given this time series specification, the unconditional cross-sectional asset pricing that we are interested in testing takes the form

$$
E\left[\bar{r}_{n}\right]=\beta_{n, \theta} \lambda_{\theta}
$$

where $\bar{r}_{n}$ represents the average time-series return for portfolio $n, \lambda_{\theta}$ represents the private investment self-financing premium, and the expectations operator is applied cross-

\footnotetext{
${ }^{7}$ The main difference is that private business owners typically hold a very large portion of their wealth in their private business, so the assumption of risk neutrality in Froot et al's model is less realistic. However, adding risk aversion would only make the profit function in their model more concave, generally increasing the magnitude of their results when applied to our context.
} 
sectionally. The sign on $\lambda_{\theta}$ is predicted to be negative since the private investment hedging motive increases demand and lowers the expected return for assets whose payoffs are positively correlated with self-financing needs.

\section{Estimation}

\subsection{Private Investment Self-Financing Needs}

Since private investment self-financing needs are not directly observable, a proxy is needed to estimate Equation (2). With constant external financing costs, realized private investment growth, $I_{t}$, will be positively related to self-financing needs since private business owners will require more external financing to undertake more expansion projects, all else equal. Since some investment projects require multiple periods of planning and financing to bring to fruition, and since some financing is required at the time of project implementation and reporting, we specify aggregate self-financing needs as a linear function of realized private investment growth, expected future private investment growth, and an interaction term:

$$
\theta_{t}=b_{0}+b_{1} I_{t}+b_{2} E_{t}\left[I_{t+1}\right]+b_{3} I_{t} E_{t}\left[I_{t+1}\right],
$$

This equation can be substituted into Equation (1) to obtain

$$
r_{n, t}=\alpha_{n}+\beta_{n, \theta}\left(b_{0}+b_{1} I_{t}+b_{2} E_{t}\left[I_{t+1}\right]+b_{3} I_{t} E_{t}\left[I_{t+1}\right]\right)+\varepsilon_{n, t} .
$$

We also specify that future expected private investment can be linearly forecasted by $k$ macroeconomic variables, $z_{1, t}, z_{2, t}, \ldots z_{k, t}$, that are observable in period $t$ :

$$
E_{t}\left[I_{t+1}\right]=c_{0}+c_{1} z_{1, t}+c_{2} z_{2, t}+\ldots+c_{k} z_{k, t} .
$$


Taking equations (2), (4), and (5) together, we can test the private investment model by using a cross-sectional model of the following form

$$
E\left[\bar{r}_{n}\right]=\lambda_{0}+\lambda_{1} \widetilde{b}_{n, 1}+\lambda_{2} \widetilde{b}_{n, 2}+\lambda_{3} \widetilde{b}_{n, 3}
$$

where $\widetilde{b}_{n, k}$ represents $\beta_{n, \theta} b_{k}$ from Equation (4).

\subsection{Estimation Methodology}

Our asset pricing tests are performed using both the generalized method of moments (GMM) approach and the classic two-pass Fama-MacBeth regression. We choose both approaches to check the statistical robustness of our results. We first describe the GMM approach and then we explain the Fama-Macbeth regression procedure.

Since we will be comparing our results to other models, we will consider the general case of $k$ factors and $n$ testing assets. Defining $\lambda=\left(\lambda_{1}, \ldots, \lambda_{k}\right)^{\prime}$ as the vector of risk premiums, we can write a model's cross-sectional asset pricing equation as

$$
E\left[R_{t}\right]=\lambda_{0} \mathbf{1}_{N}+\Sigma_{r f} \Sigma_{f}^{-1} \lambda
$$

where $E\left[R_{t}\right]$ represents the n-vector of expected returns on assets, $\left(E\left[r_{1, t}\right], \ldots, E\left[r_{n, t}\right]\right)^{\prime}$ and $\Sigma_{r f} \Sigma_{f}^{-1}$ represents the multivariate-regression coefficient matrix with $\Sigma_{r f}$ representing the variance-covariance matrix of returns and factors and $\Sigma_{f}^{-1}$ representing the inverse of the variance-covariance matrix of factors. This is the asset pricing equation incorporating multivariate coefficients. The univariate counterpart is

$$
E\left[R_{t}\right]=\lambda_{0} \mathbf{1}_{N}+\lambda_{1} \frac{\operatorname{cov}\left(R_{t}, f_{1}\right)}{\sigma_{1}^{2}}+\cdots+\lambda_{k} \frac{\operatorname{cov}\left(R_{t}, f_{k}\right)}{\sigma_{k}^{2}}
$$

where $\sigma_{k}^{2}$ is the variance of the $k$ th factor, $\frac{\operatorname{cov}\left(R_{t}, f_{k}\right)}{\sigma_{k}^{2}}$ is the n-vector of coefficients from the 
univariate regression of $R_{t}$ on $f_{k}$, and $\lambda_{k}$ is the risk premium for $f_{k}$.

While most multifactor applications of the Fama-MacBeth methodology employ multivariate betas from time-series regressions of returns on the $k$ factors, Jagannathan and Wang (1998) consider the case of two-pass estimation with univariate betas. We consider both the multivariate and the univariate betas for our private investment model. We follow Shanken and Zhou (2007) and employ a sequential, two-step GMM estimation. This approach, which builds on Harvey and Kirby (1995), uses the fact that betas can be represented in terms of moments involving the covariance matrix between the returns and the factors and the covariance matrix of the factors. The alphas from Equation (1) do not need to be separately identified. The specific GMM formulation we use and describe below has the advantage of numerical stability and tractability, as argued for in Shanken and Zhou (2007).

Using multivariate coefficients, the sample moment conditions are

$$
E\left[\begin{array}{c}
R_{t}-\mu_{r} \\
F_{t}-\mu_{f} \\
\left(f_{1, t}-\mu_{1}\right)^{2}-\sigma_{1}^{2} \\
\vdots \\
\left(f_{k, t}-\mu_{k}\right)^{2}-\sigma_{k}^{2} \\
\left(f_{i, t}-\mu_{i}\right)\left(f_{j, t}-\mu_{j}\right)-\operatorname{cov}\left(f_{i, t}, f_{j, t}\right) \\
R_{t}-\lambda_{0} \mathbf{1}_{N}+\Sigma_{r f t} \Sigma_{f}^{-1} \lambda
\end{array}\right]=0 .
$$

The first and second moment conditions (in matrix form) exactly identify $n+k$ parameters as the expected returns on assets and factors. The following moment conditions identify the $k(k+1) / 2$ parameters as the variances and covariances of the $k$ factors. The last $n$ moment conditions are the cross-sectional asset pricing model. This last set of moment conditions 
is overidentified as long as the $k+1$ asset pricing parameters $(\lambda \mathrm{s})$ is less than the number of assets $n$.

The first step in estimating this system of moment conditions is to estimate the sample means, variances and covariances of the asset returns and factors. The second step is to plug these estimates into the last $n$ moment conditions for estimation of the $\lambda$ s. The last set of moment conditions is expressed for the multivariate beta case. For the univariate case, this last set of moment conditions is replaced with Equation (8).

We perform three kinds of tests in our GMM framework. The first test we use is Hansen's (1982) J-statistic of overidentifying restrictions. The second test we use is the $\Delta \mathrm{J}$ test of Newey and West (1987) which follows a chi-squared distribution with degrees of freedom equal to the number of restrictions,

$$
T J_{\text {restricted }}-T J_{\text {unrestricted }} \sim \chi^{2} \text { (number of restrictions) }
$$

where $T$ is the number of time-series observations and $J$ is the minimized objective function value from the second-stage GMM estimation. This test reports whether an additional factor adds explanatory power to a given model. The unrestricted model is estimated using the model explanatory factors plus an additional test factor. The restricted model is estimated using only the model explanatory factors. The null hypothesis is that the restricted model is correct so that the additional test factor does not add explanatory power. Because these are nested tests, the weighting matrix of the unrestricted model is used in both the restricted and unrestricted GMM procedures. The third test we use is a standard Wald statistic for the same restriction used in the $\Delta J$ test. $^{8}$

For the Fama-MacBeth regressions, the estimation procedure is undertaken in two stages. In the first stage, $n$ ordinary least squares (OLS) time-series regressions are used

\footnotetext{
${ }^{8}$ For details, see pages $549-550$ of Greene (2003).
} 
to estimate $\beta$ s. In the second stage, an OLS cross-sectional regression is used on expected returns and the estimated $\beta$ s from the first stage. This regression procedure is widely used in asset pricing, but it suffers from an errors-in-variables problem with respect to the firststage $\beta$ s. To correct for this problem, we adjust the standard errors from the second-stage cross-sectional regression following Shanken (1992). In addition to a standard adjusted R-squared measure, we report the T-squared test for pricing errors described in Shanken (1985) and Lewellen, Nagel and Shanken (2009). The test statistic follows a finite-sample $F$ distribution and the null hypothesis is that the pricing errors of the cross-sectional regression are equal to zero. There is an additional source of errors-in-variable due to our forecast of private investment growth in our time-series regressions. Because of this, we also use bootstrap methods to check the robustness of our results.

The cross-sectional $R^{2}$ measure employed by Jagannathan and Wang (1996), Lettau and Ludvigson (2001), and Petkova (2006) can summarize the goodness of fit of each model. This measure is calculated as

$$
R^{2}=\frac{\operatorname{Var}_{c}\left(\bar{R}_{n}\right)-\operatorname{Var}_{c}\left(\bar{e}_{n}\right)}{\operatorname{Var}_{c}\left(\bar{R}_{n}\right)}
$$

where $\bar{R}_{n}$ is the time-series average of the return to portfolio $n, \operatorname{Var}_{c}(\cdot)$ is the in-sample cross-sectional variance, and $\bar{e}_{n}$ is the time-series average of the pricing error for portfolio $n$ in the cross-sectional regressions. To account for different number of factors across models, we choose to report adjusted $R^{2}$, which is defined as

$$
\operatorname{Adj} R^{2}=1-\left(1-R^{2}\right) \frac{n-1}{n-k-1},
$$

where $n$ is the number of testing assets and $k$ is the number of factors. Although the cross-sectional $R^{2}$ is not a formal test of model specification, it is an informative summary statistic of how well each model fits the data. 


\subsection{Data}

Among the test portfolios we use are the 25 size- and value-sorted monthly portfolios used in Fama and French (1993), formed from the intersection of size-and value-sorted portfolio quintiles, rebalanced monthly. ${ }^{9}$ In addition to the 25 size and value portfolios, we also use as test assets 10 distress-sorted portfolios formed according to Campbell, Hilscher and Szilagyi (2008). ${ }^{10}$ Campbell et al. use accounting and equity market variables to forecast 12month-ahead probabilities that firms will become financially distressed. Surprisingly, they find that more distressed firms trade at price premium and exhibit lower average returns compared to non-distressed firms. This is opposite what most rational asset pricing models would predict since more distressed firms have higher market betas. Following Li, Vassalou and Xing (2006), we compute quarterly returns by compounding the three monthly returns of each quarter for all 35 test portfolios, since investment growth rates are only available quarterly; we also subtract the three-month Treasury bill rate obtained from CRSP using the last observation of the previous quarter as the riskless rate for the next quarter.

We compare our private investment results with the size and value factors of Fama and French (1993), where the size factor, $\mathrm{SMB}_{t}$ ("small minus big"), is formed by taking the average return on a portfolio of small stocks (based on market capitalization) minus the average return on a portfolio of big stocks, and the value factor, $\mathrm{HML}_{t}$ ("high minus low"), is formed by taking the average return on a portfolio of value stocks (based on a high ratio of book equity to market equity) minus the average return on a portfolio of growth stocks (low book-to-market ratio). We also compare our private investment results with the investment and return-on-equity factors of Chen, Novy-Marx and Zhang (2011), where the investment factor, INV, is formed as the difference between low-investment and high-investment firm

\footnotetext{
${ }^{9}$ The data and details can be found at Kenneth French's website which is currently located at: http://mba.tuck.dartmouth.edu/pages/faculty/ken.french/.

${ }^{10}$ We thank Lu Zhang for providing this data at his website and refer readers there for details regarding the portfolio construction. Again, we form quarterly returns by compounding their monthly returns.
} 
returns, and the return-on-equity factor, ROE, is formed as the difference between highreturn-on-equity and low-return-on-equity firm returns. Fama and French, as well as Chen, Novy-Marx, and Zhang, use an excess market return factor (XMKT) which we form based on a value-weighted return using all NYSE, AMEX, and NASDAQ stocks available from CRSP minus the three-month Treasury bill rate from CRSP using the last observation of the previous quarter as the riskless rate for the next quarter.

Following Li, Vassalou and Xing (2006), we use seasonally-adjusted macro data from the Bureau of Economic Analysis and construct the noncorporate investment growth factor $\left(\mathrm{NCOR}_{t}\right)$ by taking the growth rate of noncorporate investment defined as noncorporate fixed investment (residential and nonresidential, excluding farms) plus changes in noncorporate private inventories. The noncorporate sector comprises partnerships, limited liability companies, sole proprietorships, and individuals who receive rental income, and does not include S- or C-corporations. The Federal Reserve Board notes that, "Firms in the [noncorporate] sector generally do not have access to capital markets, and to a great extent, rely for their funding on loans from commercial banks and other credit providers (including federal government) and on trade credit from other firms." 11 In the empirical analysis below, we use noncorporate investment growth as the proxy measure for private investment growth. The other macro variables used in our analysis are described in the next subsection. All variables are deflated using the personal consumption expenditure chain-type price deflator, as in Lettau and Ludvigson (2001).

\subsection{Estimation of Planned Private Investment}

As a proxy for private investment plans, we use forecasted noncorporate investment growth, $E_{t}\left[\mathrm{NCOR}_{t+1}\right]$, based on the following macroeconomic predictive variables: market excess returns, $\mathrm{XMKT}_{t}$, as described above in Section 3.3; the credit spread, $\mathrm{CRED}_{t}$, constructed

\footnotetext{
${ }^{11}$ From "A Guide to the Flow of Funds Accounts," Board of Governors of the Federal Reserve System.
} 
as the spread between Moody's BAA and AAA corporate bonds; a measure of the slope of the term structure, $\mathrm{TERM}_{t}$, constructed as the difference between the return on 30year government bonds and a one-month T-bill; and growth in non-government employee compensation, $\mathrm{COMP}_{t}$. This choice of explanatory variables is similar to that found in Lettau and Ludvigson (2002) in predicting aggregate private investment growth of the noncorporate and corporate sectors. Our approach compares to theirs as follows: first, we predict investment growth just in the noncorporate sector since that is the basis of our private investment theory; second, we include inventories whereas they exclude inventories, since this is the approach taken in Li, Vassalou and Xing (2006); third, we use excess market returns (XMKT) as a simpler way of capturing two of their variables, namely their $\log$ measure of the dividend price ratio for $\mathrm{S} \& \mathrm{P} 500$ stocks and their detrended short-term interest rate; fourth, we use growth in employee compensation (COMP) instead of their measure of cay (a cointegrating residual for consumption, asset wealth and labor income) in order to avoid the controversial nature of their results. ${ }^{12}$ Although we tried several other macroeconomic predictive variables, including the specification of Lettau and Ludvigson (2002), we found that it had very little effect on the results reported in this and other sections of our study.

Panel A of Table 1 shows the results of our construction of $E_{t}\left[\mathrm{NCOR}_{t+1}\right]$ from the regression

$$
\mathrm{NCOR}_{t+1}=c_{0}+c_{1} \mathrm{XMKT}_{t}+c_{2} \mathrm{CRED}_{t}+c_{3} \mathrm{TERM}_{t}+c_{4} \mathrm{COMP}_{t}+v_{t}
$$

The coefficient estimates have the expected sign, positive for all terms except the credit spread which has a negative sign. Employee compensation growth, COMP, has the most statistically and economically significant predictive effect with a coefficient estimate of 2.84

\footnotetext{
${ }^{12}$ See the criticism of Brennan and Xia (2005) and the response of Lettau and Ludvigson (2005).
} 
and a t-value of 4.74. The overall R-squared for the regression is a moderate $17 \% .{ }^{13}$ In Figure 1 we plot $\mathrm{NCOR}_{t}$ and our forecast of $\mathrm{NCOR}_{t+1}, E_{t}\left[\mathrm{NCOR}_{t+1}\right]$. As can be seen in the figure, there is a sharp decline in predicted and realized noncorporate investment growth during the financial crisis of 2007 and 2008. Because of this, we analyze the effect of dropping these years in the discussion below. In panels $\mathrm{B}$ and $\mathrm{C}$ of Table 1 we report the correlation coefficient of key macroeconomic and financial variables. Correlations are generally low and have signs that make sense in light of the findings of previous studies.

Next, we consider how noncorporate investment growth changes with credit conditions. To do this, we divide our sample into subperiods according to whether the credit spread variable is high, above the mean of its realizations, or low, below the mean of its realizations. ${ }^{14}$ Using these subsamples, we regress $\mathrm{NCOR}_{t+1}$ on $\mathrm{XMKT}_{t}, \mathrm{CRED}_{t}, \mathrm{TERM}_{t}$, and proprietary income growth, $\mathrm{PROP}_{t+1} \cdot{ }^{15}$ During a credit boom, when the credit spread is low, we find that $\mathrm{XMKT}_{t}, \mathrm{CRED}_{t}, \mathrm{TERM}_{t}$, and $\mathrm{PROP}_{t+1}$ are insignificantly related to the subsequent quarter's noncorporate investment growth. This result is shown in Panel A of Table 2 and is consistent with the idea that external financing costs are mild during credit booms, so credit conditions and private business income do not have predictable effects on investment activity. In contrast, during a credit crunch, when the credit spread is high, we find that $\mathrm{CRED}_{t}$ and $\mathrm{TERM}_{t}$ are significantly negatively related to noncorporate investment growth. This is consistent with the idea that private investment is more

\footnotetext{
${ }^{13}$ Lettau and Ludvigson (2002) report an R-squared of $22 \%$ in their Table 2 when predicting aggregate investment growth in the corporate and noncorporate sectors, excluding inventories. This level of explanatory power also accords with the R-squared of $16 \%$ found in Table 2 of Vassalou (2003) for predicting aggregate GDP growth.

${ }^{14}$ Following Petkova and Zhang (2005), we will subsequently analyze our asset pricing results across the credit cycle. We thus use the mean here since this is the method Petkova and Zhang use.

${ }^{15}$ We regress $\mathrm{NCOR}_{t+1}$ on $\mathrm{PROP}_{t+1}$ in order to check for investment-cash flow sensitivity. We use $\mathrm{XMKT}_{t}, \mathrm{CRED}_{t}$, and $\mathrm{TERM}_{t}$ as explanatory variables since they measure the investment opportunities and credit conditions associated with investment planning for the next quarter. This follows the timing used in Equation (13) to construct $E_{t}\left[\mathrm{NCOR}_{t+1}\right]$. In unreported results, we tried using $\mathrm{NCOR}_{t}$ as the explanatory variable in Equation (13), but we found that $\mathrm{CRED}_{t}$ was not significant.
} 
sensitive to credit conditions in a credit crunch, when credit constraints are more binding, than in a credit boom. We also find that during a credit crunch, proprietary income growth is significantly related to noncorporate investment growth, in accordance with the investment-cash flow sensitivity hypothesis of Fazzari, Hubbard and Petersen (1988) who argue that investment-cash flow sensitivity is evidence of costly external financing. ${ }^{16}$ Panel B of Table 2 shows statistics for these credit variables across the full sample and for credit boom and credit crunch subsamples.

\section{Asset Pricing Results}

\subsection{Main Results}

The methodology in this section follows generalized method of moments (GMM) procedure using multivariate betas described in Shanken and Zhou (2007). ${ }^{17}$ The results are shown in Panel A of Table 3. Consistent with the private investment model prediction, we find a negative and significant risk premium associated with the noncorporate investment factor, $\mathrm{NCOR}_{t}$ and forecasted noncorporate investment growth, $\mathrm{E}_{t}\left[\mathrm{NCOR}_{t+1}\right]$. The coefficient for the cross-term is significantly positive. The reason for this is related to the fact that estimated time-series coefficients tend to be positive for expected future investment growth and negative for contemporaneous investment growth. We will discuss this issue further below in Section 4.3.

For comparison, results for the 3-factor Fama-French model are shown in Table 3, Panel B. The coefficient on excess market returns is negative and significant. This is in accordance with the puzzling result found in Campbell, Hilscher and Szilagyi (2008) that

\footnotetext{
${ }^{16}$ See Hovakimian and Hovakimian (2009) for a more recent study and survey of the literature related to time-varying investment-cash flow sensitivity.

${ }^{17}$ The estimator we use is the "GMM2" estimator in Shanken and Zhou's notation.
} 
high-distress portfolios tend to have higher market betas but lower expected returns than low-distress portfolios. Although the R-squared and J-test suggest that the Fama-French model fits the data slightly better than our private investment model, we find using $\Delta J$ and Wald tests that our model adds to the explanatory power of the Fama-French model. Again, however, our focus is not to win a horse race with the Fama-French model, but to give an account which yields results that are consistent with theoretical predictions.

Results for the 3-factor Chen, Novy-Marx, and Zhang (CNZ) model are shown in Table 3, Panel C. The CNZ model performs well with coefficients having the theoretically predicted signs. Their model, however, is improved in a statistically significant way when our measure of noncorporate investment growth is added to the model (we also find that their factors add explanatory power to our model, as reported in Panel A). Our model can, therefore, be interpreted in light of the CNZ model as either offering an alternative but not-mutuallyexclusive theoretical account, or as offering a complementary account of how asset prices of our test assets behave.

Table 4 shows that our results are robust to the univariate GMM methodology described in Shanken and Zhou (2007). The constant, R-squared and specification test remain unchanged and the other coefficient estimates and test statistics are similar.

Comparing our private investment results to the Fama-French and CNZ models, we obtain a positive and significant constant term in the multivariate GMM approach of 4.2\%; the estimates for the Fama-French and CNZ models are $7 \%$ and $-1 \%$ respectively. Since this term should theoretically be zero, our model could be said to perform better than the Fama-French model but not as good as the CNZ model. Using a specification J-test for each model, we obtain a p-value of 0.84 which compares favorably to the p-value of 0.78 for the Fama-French model and is the same as the p-value of 0.84 for CNZ, though all 3 models fail to be rejected.

In panels $\mathrm{A}, \mathrm{B}$ and $\mathrm{C}$ of Table 5, we use Fama-Macbeth regressions and report results of 
our model, the Fama-French 3-factor model, and the model of Chen, Novy-Marx, and Zhang (2011), repsectively. These results are very similar to what we found with the GMM results discussed above, although test statistics are less statistically significant due to the relatively weaker power of the Fama-MacBeth methodology. Our model obtains a lower adjusted Rsquared than the Fama-French and CNZ models, 70\%, 79\% and 83\% respectively. However, the $T^{2}$ test of pricing errors, based on Shanken (1985) and Lewellen, Nagel and Shanken (2009), suggests that our model yields better statistical properties than the Fama-French and CNZ models, with p-values of $0.628,0.061$, and $0.449 .{ }^{18}$ We stress, however, that our main contribution is not to win a horse race with the Fama-French or CNZ models, but to offer an alternative, rational model that can explain the estimated signs on the risk premia for size-, value- and distress-sorted portfolios. In panels D, E and F we check how dropping the financial crisis years 2007 and 2008 affects our results and find results that are very similar.

\subsection{Comparison with Other Models and Robustness}

Building on the work of Cochrane (1996), Li, Vassalou and Xing (2006) show that using investment growth from different sectors of the economy can go a long way toward explaining the cross-section of size, value and distress portfolios. To make our work more directly comparable to Li et al. (2006), we use Fama-MacBeth methodology for this comparison (and for subsequent comparisons). Panel A of Table 6 shows the results of using as factors growth rates of investment for various sectors: household (HHOLDS), corporate (NFINCO), noncorporate (NCOR), and financial (FINAN). For the full sample the model can only explain $42 \%$ of the variation in average returns for the 25 Fama-French and 10 distress portfolios, based on the adjusted R-squared from Fama-MacBeth regressions. The constant

\footnotetext{
${ }^{18}$ Our Fama-French $T^{2}$ result is consistent with that found in Petkova (2006).
} 
term, however, is estimated to be only 1.5\%, lower than both the Fama-French model and our private investment model.

Although investment factors by themselves seem to explain the size- and value-sorted portfolios fairly well, they do not do a very good job of explaining the distress-sorted portfolios. Our findings thus indicate the importance of adding measures of expected future private investment in order to explain the distress-sorted portfolios. At first blush it is somewhat surprising that when nonfinancial corporate investment growth is included in a multivariate regression model without interaction terms, the sign on the noncorporate investment growth factor becomes positive and not significant. Below, we further explore how this result is driven by the way that the distress-sorted portfolio returns interact with the explanatory variable variables of this specification.

To compare our results with Heaton and Lucas (2000), we also test a model using as factors excess market returns (XMKT), proprietary income growth (PROP), labor compensation growth (COMP), and the credit spread (CRED). We find that this model can explain $77 \%$ of return variation using the 25 Fama-French and 10 distress portfolios, as shown in Panel B of Table 6. The coefficient on aggregate proprietary income growth is significant and negative. This is puzzling from the income-diversification perspective motivating the Heaton-Lucas model: if private business owners are risk averse then they have an incentive to diversify their exposure to private business income risk, which should lead to a positive return premium for proprietary income growth, not a negative premium as found in the data. From a private investment perspective, however, the negative return premium makes sense: inasmuch as proprietary income growth is positively correlated with investment opportunities, assets whose payoffs are correlated with proprietary income growth will be good hedges to self-financing needs and will therefore be traded at a premium and have a negative return premium.

In panels C and D of Table 6, we exclude the years 2007-2008 and report Fama-MacBeth 
regression results for the Li-Vassalou-Xing model and the Heaton-Lucas model. The adjusted R-squared decreases for these models, the intercept increases, and the changes in the t-statistics vary. In short, we again find that model results are not particularly sensitive to the 2007-2008 financial crisis years.

\subsection{Distress Portfolio Betas and Returns}

In figures 2 and 3, we show a plot of the first-pass Fama-Macbeth time-series betas against expected returns for the 10 distress portfolios for the factors of each of the models considered above. For our private investment specification, Panel (a) of Figure 2 shows that the beta for NCOR of the most highly distressed portfolio (D10) is an outlier relative to the other portfolios. This is consistent with the fact that we obtain a low t-statistic on NCOR in our Fama-MacBeth regressions. In contrast, as shown in Panel (b) of Figure 2, the distress portfolio betas for $E_{t}\left[\mathrm{NCOR}_{t+1}\right]$ follow a generally linear, negative relationship with the average returns of each portfolio with the low average returns for D10 corresponding to a high beta on expected noncorporate investment. This is consistent with our private investment explanation: distressed portfolios are highly correlated with planned private investment and therefore comprise a good hedge for self-financing needs. Also worth noting is the negative estimated coefficients on NCOR. This is consistent with the finding in $\mathrm{Li}$, Vassalou, and Xing (2006), and our finding in Table 1 that the correlation between $\mathrm{XMKT}_{t}$ and $\mathrm{NCOR}_{t}$ is negative. This suggests that there are important cyclical effects regarding the timing of favorable expectations for future investment opportunities, as reflected by forwardlooking stock prices, and the realization and reporting of investment projects. Although expectations and planning of private investment projects is positively correlated with market returns, the realization of private investment growth is actually negatively correlated with market returns.

For the Fama-French model, Panel (c) of Figure 2 shows that the beta on excess market 
returns also exhibits a generally linear relationship with average portfolio returns. This explains how these models are able to obtain a high adjusted R-squared in the Fama-MacBeth regressions, but it also underscores the finding of Campbell et al. (2008) that distressed portfolios are puzzling from the perspective of standard models: distressed portfolios have lower average returns but higher betas than their less distressed counterparts. From the perspective of our private investment model, however, this positive relationship can be understood rationally: positive excess market returns signal better investment expansion opportunities, so portfolio returns that are highly correlated with XMKT are better hedges for self-financing needs and thus exhibit lower average returns. Similar to XMKT, Panel (d) of Figure 2 shows that the relationship between SMB betas and distressed portfolio returns is negative, a similarly puzzling finding in light of portfolio-diversification models. As shown in Panel (e) of Figure 2, the relationship between HML and distress portfolio returns is rather sporadic without displaying a clean pattern. This underscores the importance of XMKT as to obtaining a high degree of explanatory power in the Fama-French model with distress-sorted portfolios. In unreported regressions we find that when XMKT is dropped from the Fama-French model the adjusted R-squared drops from $79 \%$ to $40 \%$.

As shown in panels (a) through (d) in Figure 3, for the Li-Vassalou-Xing model we find that investment in the household sector, HHLDS, and the financial sector, FINAN, have betas with a generally linear, negative relationship to the average returns of distress portfolios. The relationship between nonfinancial corporate investment (NFINCO) betas and average distress portfolio returns is positive. ${ }^{19}$ This is rather surprising since the risk premium coefficient is found to be negative. This underscores a tension in the Li-VassalouXing model between explaining the size and value portfolios and the distress portfolios:

\footnotetext{
${ }^{19}$ We find betas that are generally negative for distress-sorted portfolios, just as Li, Vassalou and Xing (2006) find for size- and value-sorted portfolios. The distress portfolio betas for NCOR are generally positive in our Li-Vassalou-Xing specification, in contrast to the finding in our private investment specification. This is because of multicollinearity between NCOR and NFINCO in the Li-Vassalou-Xing specification.
} 
although the relationship for NFINCO between the distress portfolio betas and returns is positive, the relation for the size and value portfolios is negative, and it is the size and value effect that dominates. Related to this tension, the coefficient for noncorporate investment growth, NCOR, is positive, though not significant, even though though the coefficient for NCOR was found to be positive in the private investment model. These results are driven by the interactive effects between the several test portfolios and explanatory factors.

As shown in panels (e) through (h), for the Heaton-Lucas model, we find a generally negative, linear relation between XMKT betas and average distress portfolio returns, just as we found with the Fama-French model. We also find a generally negative, linear relation between the betas on aggregate employee compensation growth, COMP, and average distress portfolio returns. This contradicts portfolio-diversification-based theory that would predict a positive relation. However, this result is not particularly surprising from the private investment model point of the view: $\mathrm{COMP}_{t}$ is a positive predictor of noncorporate investment growth, as reported above in section 3.4, and so it is a positive predictor of future self-financing needs, and so the sign on the estimated risk premium is negative. The relationship between the credit spread betas and the distress portfolio returns is generally negative but not particularly clean. However, the estimated risk premium coefficient for CRED in the Heaton-Lucas model is positive. Like the NFINCO relationship discussed above for the Li-Vassalou-Xing model, this result signals a similar tension which underscores the importance of the size and value portfolios in determining the sign on the estimated coefficient for CRED, in this case.

\subsection{Credit Crunch and Credit Boom Periods}

To analyze the effect of time-varying credit conditions, we follow the dummy-variable procedure outlined in Debondt and Thaler (1987) and Chan (1988), and that is followed by Petkova and Zhang (2005). That is, we consider the asset pricing performance of our model 
using a macroeconomic-dependent dummy variable multiplied by our asset pricing factors. More specifically, we set a dummy variable equal to 1 when $\mathrm{CRED}_{t}$ is greater than its mean, and we multiply this dummy variable, and one minus this dummy variable, by our two main factors, $\mathrm{NCOR}_{t}$ and our forecast of $E_{t}\left[\mathrm{NCOR}_{t+1}\right]$. The GMM results for this approach are shown in Panel A of Table 7. In Panel B we use a similar approach based on quartile cutoffs of $\mathrm{CRED}_{t}$ rather than the mean.

We find that the coefficient on $E_{t}\left[\mathrm{NCOR}_{t+1}\right]$ is more negative in credit boom periods than in credit crunch periods and we find that the coefficient on $\mathrm{NCOR}_{t}$ is more negative in credit crunch periods than in credit boom periods. From the perspective of private investment, this finding can be interpreted as follows. In credit boom periods, self-financing needs tend to be more correlated with private investment plans, whereas in credit crunch periods self-financing needs tend to be more correlated with contemporaneous investment that has already been been committed to. Thus, observing a stronger effect of future expected investment in credit crunch periods and a stronger effect of contemporaneous investment in credit crunch periods is consistent with the changing nature of self-financing needs across credit cycles.

\section{$5 \quad$ Bootstrap Analysis}

The results so far suggest that the betas with respect to noncorporate investment growth, $\mathrm{NCOR}_{t}$, and forecasted noncorporate investment growth, $\mathrm{E}_{t}\left[\mathrm{NCOR}_{t+1}\right]$, explain nearly $70 \%$ of the cross-sectional differences in average returns. However, the forecasted factor variable $\mathrm{E}_{t}\left[\mathrm{NCOR}_{t+1}\right]$ is not observable and needs to be estimated by the auxiliary regression described in Section 3.4. This leads to the problem of generated regressors. According to Pagan (1984) and Hoffman (1987), if a generated regressor represents the unanticipated 
part of a variable ${ }^{20}$ the OLS estimates of the parameters' standard errors will still be correct. On the other hand, if a generated regressor represents the forecasted part, then a downward bias may appear in the estimation of the standard errors. ${ }^{21}$ Although the GMM estimation accounts for the effects of generated regressors in a natural and elegant way (Cochrane, 2005), it is still beneficial to obtain the correct standard errors for the FamaMacBeth regressions through bootstrapping to gain additional insight into the robustness and properties of the estimation.

Bootstrapping has been used in several papers in the asset pricing area, such as Petkova (2006) and Kosowski, Timmermann, Wermers and White (2006). It generates small-sample empirical distributions of different parameters of interest. The bootstrapped t-statistics can be calculated from the distributions. Those t-statistics take into account the generated regressors effects and are expected to be smaller than the OLS counterparts. It will also help confirm that the empirical results reported so far in the paper reflect the presence of significant state variable risk premia rather than random factors.

Our regression specification consists of three parts. First, the auxiliary regression estimates the forecasted noncorporate investment growth. Second, this predicted variable enters the time-series regressions as a factor. Along with other factors that are directly observed, betas are estimated for each asset. Third, betas from the previous step are used in the cross-sectional regression to estimate risk premia. The estimation errors from both the auxiliary and the time-series regressions could bias the standard errors of the risk premia. ${ }^{22}$

Building on the work of Kosowski, Timmermann, Wermers and White (2006), Smith and Mcaleer (1993), and Petkova (2006), our bootstrap analysis is designed in two ways

\footnotetext{
${ }^{20}$ For example, unlagged residuals estimated from an auxiliary regression.

${ }^{21}$ Pagan (1984) shows the use of predictors or residuals from an auxiliary regression does not necessarily lead to efficiency losses or incorrect standard errors and even when they do, this does not necessarily invalidate the conclusions.

${ }^{22}$ Shanken's correction accounts for the estimation errors from the time-series regressions, but it still leaves out the estimation error from the auxiliary regression.
} 
depending on the contemporaneous relation between the auxiliary and the time-series regressions. If we treat the two as a system, their residuals are bootstrapped in a manner that maintains the contemporaneous relation. Alternatively, their residuals can be bootstrapped independently. We refer to our first approach as a system bootstrap and the second approach as an independent bootstrap.

The system bootstrap is designed as follows. First, forecasted private investment growth $E_{t}\left[\mathrm{NCOR}_{t+1}\right]$ is estimated by an auxiliary regression as in Section 3.4 and reported in Table 1:

$$
\mathrm{NCOR}_{t+1}=c_{0}+c_{1} \mathrm{XMKT}_{t}+c_{2} \mathrm{CRED}_{t}+c_{3} \mathrm{TERM}_{t}+c_{4} \mathrm{COMP}_{t}+v_{t} .
$$

Second, factor loadings for the 25 Fama-French size- and value-sorted portfolios and the 10 distress-sorted portfolios are estimated from time-series regressions:

$$
\begin{aligned}
r_{n, t}= & \alpha_{n}+\beta_{n, 1} \mathrm{NCOR}_{t}+\beta_{n, 2} E_{t}\left[\mathrm{NCOR}_{t+1}\right] \\
& +\beta_{n, 3} \mathrm{NCOR}_{t} \cdot E_{t}\left[\mathrm{NCOR}_{t+1}\right]+\varepsilon_{n, t} .
\end{aligned}
$$

Third, we bootstrap residual vectors $\left[v_{t} \varepsilon_{t}\right]$ from the previous two steps, maintaining their contemporaneous relation. The bootstrapped residuals, denoted $\left[v_{t}^{\star} \varepsilon_{t}^{\star}\right]$, are plugged back into equations (14) and (15) in place of $v_{t}$ and $\varepsilon_{t}$ to create new dependent variables. In other words, we create $\mathrm{NCOR}_{t+1}^{\star}$ and $r_{n, t}^{\star}$ using the following equations, where $\hat{c}$ and $\hat{\beta}$ are the estimates from (14) and (15):

$$
\mathrm{NCOR}_{t+1}^{\star}=\hat{c}_{0}+\hat{c}_{1} \mathrm{XMKT}_{t}+\hat{c}_{2} \mathrm{CRED}_{t}+\hat{c}_{3} \mathrm{TERM}_{t}+\hat{c}_{4} \mathrm{COMP}_{t}+v_{t}^{\star}
$$

and

$$
\begin{aligned}
r_{n, t}^{\star}= & \hat{\alpha}_{n}+\hat{\beta}_{n, 1} \mathrm{NCOR}_{t}+\hat{\beta}_{n, 2} E_{t}\left[\mathrm{NCOR}_{t+1}\right] \\
& +\hat{\beta}_{n, 3} \mathrm{NCOR}_{t} \cdot E_{t}\left[\mathrm{NCOR}_{t+1}\right]+\varepsilon_{n, t}^{\star} .
\end{aligned}
$$


Next, given the new bootstrapped dependent variables, $\mathrm{NCOR}_{t+1}^{\star}$ and $r_{n, t}^{\star}$, regressions (14) and (15) are re-estimated. Finally, we run the cross-sectional regression to determine the risk premia associated with the factor loadings. The entire procedure is repeated 40,000 times. In this way, the small-sample distributions of the risk premia and the adjusted $R^{2}$ are generated.

In Table 8, we present quantiles for the bootstrapped distribution of risk premia and the adjusted cross-sectional $R^{2}$ s. Panel A reports the quantiles of the distribution for the risk premia of our private investment specification, along with the risk premia estimated under the null hypothesis. We find that the risk premia are not biased since the mean of each distribution is very close to the value under the null hypothesis. The t-statistics are calculated using the bootstrapped standard errors and they lead to the same statistical conclusion as the OLS counterparts. Consistent with our expectations, the bootstrapped t-statistics are smaller than the OLS t-statistics with larger disparity for the generated regressor terms. All bootstrapped t-statistics lie between the OLS and Shanken-adjusted t-statistics. $^{23}$

Panel B of Table 8 presents the finite distributions of adjusted $R^{2}$ s across all models. The bootstrap analyses for the other three models are relatively simple as they do not have an auxiliary regression. We follow the methodology in Petkova (2006) for the other three models. All adjusted $R^{2}$ s under the null hypothesis are larger than the $50 \%$ percentile except the Li-Vassalou-Xing model. This is consistent with the bootstrap results in Petkova (2006). The private investment and the Li-Vassalou-Xing models are both based on macroeconomic factors and they have larger variability in the adjusted $R^{2}$ s compared to the Fama-French and Chen, Novy-Marx, and Zhang models which use portfolio returns as factors. The Heaton-Lucas model is in between in terms of its $R^{2}$ variability in its being a hybrid model

\footnotetext{
${ }^{23}$ Even though the Shanken adjustment does not account for estimation error from the auxiliary regression, Shanken's adjustment is based on asymptotic theory and can represent a stronger adjustment than is generated via bootstrapping.
} 
of financial returns and macroeconomic factors. This has issue is discussed in Lettau and Ludvigson (2001).

As an alternative to the system bootstrap, the independent bootstrap does not treat the auxiliary regression and the time-series regressions as a system. Residuals $v_{t}$ and $\varepsilon_{t}$ are bootstrapped independently. Table 9 reports the independent bootstrap results. These results lead to the same statistical conclusions as the system bootstrap.

Despite the fact that the forecasted private investment growth and betas are estimated, the estimation of risk premia is unbiased and the bootstrapped t-statistics validate the OLS results. The model captures the fact that there are significant risk premia associated with the private investment factors.

\section{Conclusion}

In this paper we consider a private investment asset pricing model where private investment self-financing needs create an incentive for private business owners to hedge with assets that are positively correlated with self-financing needs. To test this model, we use noncorporate investment growth and future forecasted noncorporate investment growth to proxy for selffinancing needs. As evidence that self-financing needs can have significant effects, we find greater investment-cash flow sensitivity for the noncorporate business sector in credit crunch periods, when the credit spread is high, relative to credit boom periods when the credit spread is low. In asset pricing tests using size-, value- and distress-sorted portfolios, we find that the private investment model can explain about $70 \%$ of the cross-sectional variation in returns.

More importantly, the estimated risk premium coefficients have the correct sign, as predicted by the private investment model. Other leading asset pricing models do not provide an economic rationale for the estimated risk premia that we obtain in our sample. 
For example, corroborating the findings of Campbell et al. (2008), we find that high-distress portfolios have higher market betas but lower average returns than low-distress portfolios. This finding is exactly the opposite of what portfolio-diversification-based theories predict. However, from the perspective of our private investment model, this is not surprising: portfolios with high market betas are good hedges for private investment self-financing needs, and thus trade at a premium and exhibit lower expected returns. More specifically, our results suggest that high-distress portfolios comprise a good hedge for expected future investment plans in a credit boom, and a good hedge for contemporaneous self-financing needs in a credit crunch. 


\section{References}

Brennan, M. J. and Y. Xia (2005). "tay's as good as cay." Finance Research Letters, 2, $1-14$.

Cagetti, M. and M. D. Nardi (2006). "Entrepreneurship, frictions, and wealth." Journal of Political Economy, 114(5), 835-870.

Campbell, J. Y., J. Hilscher and J. Szilagyi (2008). "In search of distress risk." Journal of Finance, 63(6), 2899-2939.

Chan, K. C. (1988). "On the contrarian investment strategy." Journal of Business, 61(2), $147-63$.

Chen, L., R. Novy-Marx and L. Zhang (2011). "An alternative three-factor model." working paper.

Clementi, G. L. and H. A. Hopenhayn (2006). "A theory of financing constraints and firm dynamics." Quarterly Journal of Economics, 121(1), 229-265.

Cocco, J. F. (2005). "Portfolio choice in the presence of housing." Review of Financial Studies, 18(2), 535-567.

Cochrane, J. H. (1996). "A cross-sectional test of an investment based asset pricing model." Journal of Political Economy, 104, 572-621.

Debondt, W. F. M. and R. H. Thaler (1987). "Further evidence on investor overreaction and stock market seasonality." Journal of Finance, 42(3), 557-581.

Eisfeldt, A. L. and A. Rampini (2007). "New or used? investment with credit constraints." Journal of Monetary Economics, 54, 2656-2681.

Fama, E. F. and K. R. French (2006). "Profitability, investment, and average returns." Journal of Financial Economics, 82, 491-518. 
Fama, E. R. and K. R. French (1993). "Common risk factors in the returns on stocks and bonds." Journal of Financial Economics, 33, 3-56.

Fazzari, S. M., R. G. Hubbard and B. C. Petersen (1988). "Financing constraints and corporate investment." Brookings Papers on Economic Activity, 1988(1), 141-206.

Froot, K. A., D. S. Scharfstein and J. C. Stein (1993). "Risk management: Coordinating corporate investment and financing policies." Journal of Finance, 48(5), 1629-1658.

Gentry, W. M. and R. G. Hubbard (2004). "Entrepreneurship and household saving." Advances in Economic Analysis and Policy, 4(1), Article 8.

Gomes, J. f., A. Yaron and L. Zhang (2003). "Asset pricing implications of firms' financing constraints." working paper.

Greene, W. H. (2003). Econometric Analysis. Prentice Hall.

Hansen, L. P. (1982). "Large sample properties of generalized method of moments estimators." Econometrica, 50(4), 1029-1054.

Harvey, C. R. and C. Kirby (1995). "Analytic tests of factor pricing models." working paper, Duke University, Durham, NC.

Heaton, J. and D. Lucas (2000). "Portfolio choice and asset prices: The importance of entrepreneurial risk." Journal of Finance, 55, 1163-1198.

Hoffman, D. L. (1987). "Two-step generalized least squares estimators in multi-equation generated regressor models." Review of Economics and Statistics, 69(2), 336-346.

Holtz-Eakin, D., D. Joulfaian and H. S. Rosen (1994a). "Entrepreneurial decisions and liquidity constraints." RAND Journal of Economics, 22(5), 334-347.

Holtz-Eakin, D., D. Joulfaian and H. S. Rosen (1994b). "Sticking it out: Entrepreneurial survival and liquidity constraints." Journal of Political Economy, 102(1), 53-75. 
Hovakimian, A. and G. Hovakimian (2009). "Cash flow sensitivity of investment." European Financial Management, 15(1), 47-65.

Jagannathan, R. and Z. Wang (1996). "The conditional CAPM and the cross-section of expected returns." Journal of Finance, 51(1), 3-53.

Jagannathan, R. and Z. Wang (1998). "An asymptotic theory for estimating beta-pricing models using cross-sectional regression." Journal of Finance, 53(4), 1285-1309.

Kaplan, S. and L. Zingales (1997). "Do financing constraints explain why investment is correlated with cash flow?" Quarterly Journal of Economics, 112, 169-216.

Kerr, W. R. and R. Nanda (2009). "Democratizing entry: Banking derugulations, financing constraints, and entrepreneurship." Journal of Financial Economics, 94(1), 124-149.

Kerr, W. R. and R. Nanda (2011). "Financing constraints and entrepreneurship." In D. B. Audretsch, O. Falck and S. Heblich, eds., Handbook Of Research On Innovation And Entrepreneurship. Edward Elgar Publishing.

Kosowski, R., A. Timmermann, R. Wermers and H. White (2006). "Can mutual fund 'stars' really pick stocks? new evidence from a bootstrap analysis." Journal of Finance, 61(6), $2551-2595$.

Lamont, O., C. Polk and J. Saa-Requejo (2001). "Financial constraints and stock returns." Review of Financial Studies, 14(2), 529-554.

Lettau, M. and S. Ludvigson (2001). "Resurrecting the (C)CAPM: A cross-sectional test when risk premia are time-varying." Journal of Political Economy, 109, 1238-1287.

Lettau, M. and S. Ludvigson (2002). "Time-varying risk premia and the cost of capital: An alternative implication of the $q$ theory of investment." Journal of Monetary Economics, $49,31-66$. 
Lettau, M. and S. Ludvigson (2005). "tay's as good as cay: Reply." Finance Research Letters, 2, 15-22.

Lewellen, J. and S. Nagel (2006). "The conditional CAPM does not explain asset-pricing anomalies." Journal of Financial Economics, 82(2), 289-314.

Lewellen, J., S. Nagel and J. Shanken (2009). "A skeptical appraisal of asset pricing tests." Journal of Financial Economics. forthcoming.

Li, Q., M. Vassalou and Y. Xing (2006). "Sector investment growth rates and the crosssection of equity returns." Journal of Business, 79(3), 1637-1665.

Liu, L. X., T. M. Whited and L. Zhang (2009). "Investment-based expected stock returns." Journal of Political Economy, 117(6), 1105-1139.

Newey, W. K. and K. D. West (1987). "Hypothesis testing with efficient method of moments estimation." International Economic Review, 28(3), 777-787.

Pagan, A. (1984). "Econometric issues in the analysis of regressions with generated regressors." International Economic Review, 25(1), 221-247.

Petkova, R. (2006). "Do the Fama-French factors proxy for innovations in predictive variables?" Journal of Finance, 61(2), 581-612.

Petkova, R. and L. Zhang (2005). "Is value riskier than growth?" Journal of Financial Economics, 78(1), 187-202.

Phalippou, L. (2007). "Can risk-based theories explain the value premium?" Review of Finance, 11(2), 143-166.

Shanken, J. (1985). "Multivariate tests of the zero-beta capm." Journal of Financial Economics, $14(3), 327-348$. 
Shanken, J. (1992). "On the estimation of beta-pricing models." Review of Financial Studies, 5(1), 1-33.

Shanken, J. and G. Zhou (2007). "Estimating and testing beta pricing models: Alternative methods and their performance in simulations." Journal of Financial Economics, 84(1), $40-86$.

Smith, J. and M. Mcaleer (1993). "On the robustness of barro's new classical unemployment model." Applied Economics, 25(3), 349-360.

Stein, J. (2003). "Agency, informtaion and corporate investment." In G. Constantinides, M. Harris and R. Stulz, eds., Handbook of the Economics of Finance, pp. 111-163. North Holland.

Vassalou, M. (2003). "News related to future gdp growth as a risk factor in equity returns." Journal of Financial Economics, 68, 47-73.

Whited, T. M. and G. Wu (2006). "Financial constraints risk." Review of Financial Studies, $19(2), 531-559$. 
Table 1: Construction of $E_{t}\left[\mathrm{NCOR}_{t+1}\right]$

Panel A shows the regression of next quarter private investment growth on current macroeconomic variables with quarterly data from 1972:Q2 to 2008:Q4. The estimates from this regression are used to construct the expected private investment growth $E_{t}\left[\mathrm{NCOR}_{t+1}\right]$. The t-statistics are reported in parentheses and adjusted for autocorrelation. Panel B shows the correlation between the variables that are known to be related to the private investment growth. Panel C shows correlations between our factor variables compares to the Fama and French (1993) and Chen, Novy-Marx, and Zhang (2011) models. The variable abbreviations are as follows: XMKT is the excess market return; CRED is the credit spread, TERM is 10-year minus 1-year t-bill rate, COMP is the growth rate in aggregate U.S. employee compensation; PROP is the growth rate in aggregate U.S. proprietary income (this variable will be used in Table 2); NCOR is the growth rate in aggregate U.S. noncorporate investment; TERM is the difference between the return on 30-year government bonds and a one-month T-bill; COMP is the growth in non-government employee compensation; $E_{t}\left[\mathrm{NCOR}_{t+1}\right]$ is the our constructed forecast of noncorporate investment growth; SMB and HML are the Fama-French size and value vactors; INV and ROE are the investment and return-on-equity factors from Chen, Novy-Marx, and Zhang (2011).

Panel A: Dependent Variable $=$ NCOR $_{t+1}$

\begin{tabular}{lcccccc}
\hline & CONSTANT & $\mathrm{XMKT}_{t}$ & $\mathrm{CRED}_{t}$ & $\mathrm{TERM}_{t}$ & $\mathrm{COMP}_{t}$ & Adj $R^{2}$ \\
\hline Coefficient & -0.018 & 0.063 & -0.019 & 0.007 & 2.836 & 0.174 \\
(t-stat) & $(-1.055)$ & $(1.139)$ & $(-1.953)$ & $(1.720)$ & $(4.744)$ & \\
\hline
\end{tabular}

Panel B: Correlation Matrix of Construction Variables

\begin{tabular}{lccccccc}
\hline & $\mathrm{NCOR}_{t+1}$ & $\mathrm{NCOR}_{t}$ & $\mathrm{XMKT}_{t}$ & $\mathrm{CRED}_{t}$ & $\mathrm{TERM}_{t}$ & $\mathrm{COMP}_{t}$ & PROP $_{t+1}$ \\
\hline $\mathrm{NCOR}_{t+1}$ & 1 & & & & & & \\
$\mathrm{NCOR}_{t}$ & 0.052 & 1 & & & & & \\
$\mathrm{XMKT}_{t}$ & 0.071 & -0.070 & 1 & & & & \\
$\mathrm{CRED}_{t}$ & -0.182 & -0.113 & -0.009 & 1 & & & \\
$\mathrm{TERM}_{t}$ & -0.023 & -0.047 & 0.133 & 0.034 & 1 & & \\
$\mathrm{COMP}_{t}$ & 0.315 & 0.351 & -0.046 & -0.082 & -0.413 & 1 & \\
$\mathrm{PROP}_{t+1}$ & 0.153 & 0.052 & 0.112 & -0.108 & 0.195 & 0.104 & 1 \\
\hline
\end{tabular}

Panel C: Correlation Matrix of Asset Pricing Factor Variables

\begin{tabular}{lccccccc}
\hline & $\mathrm{NCOR}_{t}$ & $E_{t}\left[\mathrm{NCOR}_{t+1}\right]$ & $\mathrm{XMKT}_{t}$ & $\mathrm{SMB}_{t}$ & $\mathrm{HML}_{t}$ & $\mathrm{INV}_{t}$ & $\mathrm{ROE}_{t}$ \\
\hline $\mathrm{NCOR}_{t}$ & 1 & & & & & & \\
$E_{t}\left[\mathrm{NCOR}_{t+1}\right]$ & 0.052 & 1 & & & & & \\
$\mathrm{XMKT}_{t}$ & -0.070 & 0.071 & 1 & & & & \\
$\mathrm{SMB}_{t}$ & -0.150 & 0.208 & 0.417 & 1 & & & \\
$\mathrm{HML}_{t}$ & 0.054 & 0.100 & -0.434 & -0.132 & 1 & & \\
$\mathrm{INV}_{t}$ & -0.054 & 0.147 & -0.336 & -0.077 & 0.497 & 1 & \\
$\mathrm{ROE}_{t}$ & 0.064 & -0.124 & -0.287 & -0.280 & 0.112 & 0.185 & 1 \\
\hline
\end{tabular}




\section{Table 2: Cash Flow Sensitivity and Credit Conditions}

Panel A shows regression results for credit boom and credit crunch subsamples, defined by the credit spread being below or above its sample mean, respectively. The data is quarterly from 1972:Q2 to 2008:Q4. The dependent variable $\left(\mathrm{NCOR}_{t+1}\right)$ is noncorporate investment growth in the quarter $t+1$. The regressors are excess market returns $\left(\mathrm{XMKT}_{t}\right)$, credit spread $\left(\mathrm{CRED}_{t}\right)$, term structure $\left(\mathrm{TERM}_{t}\right)$, and proprietary income growth $\left(\mathrm{PROP}_{t+1}\right)$. The t-statistics are reported in parentheses and adjusted for autocorrelation. Panel B shows subsample summary statistics for the regression variables for the full sample (1972:Q2 to 2008:Q4) and for the credit boom and credit crunch subsamples. The variable $N$ reports the number of quarters used in each of the periods considered.

Panel A: Dependent Variable $=\operatorname{NCOR}_{t+1}$

\begin{tabular}{lcccccc}
\hline & CONSTANT & $\mathrm{XMKT}_{t}$ & $\mathrm{CRED}_{t}$ & $\mathrm{TERM}_{t}$ & $\mathrm{PROP}_{t+1}$ & Adj $R^{2}$ \\
\hline Boom & 0.028 & 0.075 & -0.016 & 0.005 & -0.0221 & 0.024 \\
(t-stat) & $(0.75)$ & $(0.89)$ & $(-0.35)$ & $(-0.91)$ & $(-0.08)$ & \\
& & & & & & 0.249 \\
Crunch & 0.102 & -0.002 & -0.051 & -0.018 & 0.659 & $0.58)$ \\
(t-stat) & $(2.90)$ & $(-0.02)$ & $(-2.53)$ & $(-2.40)$ & $(2.58)$ & \\
\hline
\end{tabular}

Panel B: Summary Statistics for Regression Variables $(\mathrm{N}=147)$

Full Sample

\begin{tabular}{lccccc}
\hline Variable & Mean & Std Dev & $25^{\text {th }} \%$ & Median & $75^{\text {th }} \%$ \\
\hline NCOR & 0.017 & 0.062 & -0.019 & 0.024 & 0.053 \\
XMKT & 0.011 & 0.089 & -0.035 & 0.017 & 0.065 \\
CRED & 1.110 & 0.467 & 0.780 & 0.950 & 1.300 \\
TERM & 0.951 & 1.178 & 0.120 & 0.940 & 1.750 \\
PROP & 0.017 & 0.030 & 0.005 & 0.018 & 0.033 \\
\hline
\end{tabular}

Credit Boom $(\mathrm{N}=90)$

\begin{tabular}{lcccc}
\hline Variable & Mean & Std Dev & Min & Max \\
\hline NCOR & 0.019 & 0.058 & -0.117 & 0.183 \\
XMKT & 0.007 & 0.076 & -0.266 & 0.201 \\
CRED & 0.814 & 0.143 & 0.550 & 1.090 \\
TERM & 0.824 & 1.123 & -1.290 & 3.240 \\
PROP & 0.019 & 0.025 & -0.060 & 0.105 \\
\hline
\end{tabular}

Credit Crunch $(\mathrm{N}=57)$

\begin{tabular}{lcccc}
\hline Variable & Mean & Std Dev & Min & Max \\
\hline NCOR & 0.016 & 0.067 & -0.150 & 0.128 \\
XMKT & 0.018 & 0.106 & -0.247 & 0.226 \\
CRED & 1.553 & 0.443 & 1.100 & 3.380 \\
TERM & 1.150 & 1.245 & -3.070 & 2.870 \\
PROP & 0.015 & 0.035 & -0.082 & 0.132 \\
\hline
\end{tabular}




\section{Table 3: GMM Estimation with Multivariate Betas}

This table shows the results of GMM estimations using as test assets the 25 Fama-French size- and value-sorted portfolios and 10 distress portfolios with quarterly data from 1972:Q2 to 2008:Q4. The asset pricing restrictions are expressed in terms of multivariate betas based on the regression given by

$$
E\left[R_{t}\right]=\lambda_{0} \mathbf{1}_{N}+\Sigma_{r f} \Sigma_{f}^{-1} \lambda_{a}
$$

where $E\left[R_{t}\right]$ is the $\mathrm{n}$-vector of expected returns on assets, $\left(E\left[r_{1, t}\right], \ldots, E\left[r_{n, t}\right]\right)^{\prime}$ and $\Sigma_{r f} \Sigma_{f}^{-1}$ are multivariate-regression coefficient matrices with $\Sigma_{r f}$ representing the variance-covariance matrix of returns and factors and $\Sigma_{f}^{-1}$ representing the inverse of the variance-covariance matrix of factors. The factor variables used are defined as follows: NCOR N $_{t}$ the noncorporate investment growth rate in quarter $t ; E_{t}\left[\mathrm{NCOR}_{t+1}\right]$ is the forecasted private investment growth whose construction is described in Section 3.4 and Table 1; the Frama-French factors include $\mathrm{XMKT}_{t}$, the quarter $t$ return on a value-weighted portfolio of all NYSE, AMEX, and NASDAQ stocks available in the CRSP database minus the three-month Treasury bill rate, HML ${ }_{t}$, the value factor, and $\mathrm{SMB}_{t}$, the size factor, all taken from Kenneth French's website; the Chen, Novy-Marx, and Zhang (CNZ) factors include INV, the difference between low-investment and high-investment firm returns, and ROE, the difference between high-return-on-equity and low-return-on-equity firm returns. The estimations are conducted using two-stage GMM as in, for example, Phalippou (2007) and Shanken and Zhou (2007). In Panel A, we consider the private investment model and the effect of adding extra variable(s) from the Fama-French or CNZ model to the private investment model where "combined" denotes all the preceding variables in that row being tested. In panels $\mathrm{B}$ and $\mathrm{C}$ we run similar tests on the Fama-French and CNZ models. The J-test statistic and p-value for the chi-square test of overidentifying restrictions follows Hansen (1982). The cross-sectional $\operatorname{Adj} R^{2}$ is reported for the overall goodness of fit. The $\Delta J$ test is the chi-square difference test following Newey and West (1987), where the unrestricted model is based on adding the relevant variable(s) to the model. We also report Wald test statistics for these hypothesized restrictions. For all tests, p-values are reported in the parentheses.

Panel A: Private Investment Model

\begin{tabular}{|c|c|c|c|c|}
\hline Coefficient (t-stat) & $\frac{\text { CONSTANT }}{0.042(10.126)}$ & $\frac{\mathrm{NCOR}_{t}}{-0.032(-2.319)}$ & $\frac{E_{t}\left[\mathrm{NCOR}_{t+1}\right]}{-0.022(-5.113)}$ & $\frac{\mathrm{NCOR}_{t} \cdot E_{t}\left[\mathrm{NCOR}_{t+1}\right]}{0.001(2.187)}$ \\
\hline $\begin{array}{l}J \text { (p-value) } \\
\operatorname{Adj} R^{2}\end{array}$ & $\begin{array}{c}23.224(0.841) \\
0.688\end{array}$ & & & \\
\hline $\begin{array}{l}\Delta J \text { (p-value }) \\
\text { Wald (p-value })\end{array}$ & $\begin{array}{c}\frac{\mathrm{XMKT}_{t}}{30.862(0.000)} \\
19.53(0.000)\end{array}$ & $\begin{array}{c}\frac{\mathrm{SMB}_{t}}{1.714(0.190)} \\
0.56(0.455)\end{array}$ & $\begin{array}{c}11.5 \frac{\mathrm{HML}_{t}}{85(0.001)} \\
8.57(0.003)\end{array}$ & $\begin{array}{c}\text { Combined } \\
71.610(0.000) \\
30.139(0.000)\end{array}$ \\
\hline $\begin{array}{l}\Delta J \text { (p-value }) \\
\text { Wald (p-value })\end{array}$ & & $\begin{array}{c}\mathrm{INV}_{t} \\
30.585(0.000) \\
28.744(0.000)\end{array}$ & $\begin{array}{c}\frac{\mathrm{ROE}_{t}}{16.606(0.000)} \\
12.784(0.000)\end{array}$ & $\begin{array}{c}\text { Combined } \\
50.883(0.000) \\
34.127(0.000)\end{array}$ \\
\hline
\end{tabular}

Panel B: Fama-French Model

\begin{tabular}{|c|c|c|c|c|}
\hline Coefficient (t-stat) & $\frac{\text { CONSTANT }}{0.070(10.890)}$ & $\frac{\mathrm{XMKT}_{t}}{-0.055(-6.299)}$ & $\frac{\mathrm{SMB}_{t}}{0.004(1.110)}$ & $\frac{\mathrm{HML}_{t}}{0.015(3.524)}$ \\
\hline $\begin{array}{l}J \text { (p-value) } \\
A d j R^{2}\end{array}$ & $\begin{array}{c}24.694(0.781) \\
0.773\end{array}$ & & & \\
\hline $\begin{array}{l}\Delta J \text { (p-value }) \\
\text { Wald (p-value })\end{array}$ & $\begin{array}{c}\frac{\mathrm{NCOR}_{t}}{6.322(0.012)} \\
4.53(0.033)\end{array}$ & $\begin{array}{l}\frac{E_{t}\left[\mathrm{NCOR}_{t+1}\right]}{31.838(0.000)} \\
23.125(0.000)\end{array}$ & $\begin{array}{c}\frac{\mathrm{NCOR}_{t} \cdot E_{t}\left[\mathrm{NCOR}_{t+1}\right]}{17.574(0.000)} \\
16.089(0.000)\end{array}$ & $\begin{array}{c}\text { Combined } \\
41.932(0.000) \\
27.508(0.000)\end{array}$ \\
\hline $\begin{array}{l}\Delta J \\
\text { Wald (p-value) }\end{array}$ & & $\begin{array}{c}\frac{\mathrm{INV}_{t}}{36.948(0.000)} \\
25.872(0.000)\end{array}$ & $\begin{array}{c}\frac{\mathrm{ROE}_{t}}{30.220(0.000)} \\
11.530(0.001)\end{array}$ & $\begin{array}{c}\text { Combined } \\
68.731(0.000) \\
32.546(0.000)\end{array}$ \\
\hline
\end{tabular}

Panel C: Chen, Novy-Marx and Zhang Model

\begin{tabular}{lcccc}
\hline & $\underline{\mathrm{CONSTANT}}$ & $\underline{\mathrm{XMKT}_{t}}$ & $\underline{\mathrm{INV}_{t}}$ & $\underline{\mathrm{ROE}_{t}}$ \\
Coefficient (t-stat) & $-0.008(-1.794)$ & $0.017(2.997)$ & $0.027(7.955)$ & $0.036(5.284)$ \\
\hline$J$ (p-value) & $23.239(0.840)$ & & & \\
Adj $R^{2}$ & 0.81 & & & \\
\hline & $\underline{\mathrm{NCOR}_{t}}$ & $\frac{E_{t}\left[\mathrm{NCOR}_{t+1}\right]}{4.626(0.031)}$ & $\frac{\mathrm{NCOR}_{t} \cdot E_{t}\left[\mathrm{NCOR}_{t+1}\right]}{5.197(0.023)}$ & $\underline{\text { Combined }}$ \\
$\Delta J$ (p-value) & $36.665(0.000)$ & $2.643(0.102)$ & $2.318(0.128)$ & $18.067(0.000)$ \\
$W$ ald (p-value) & $33.144(0.000)$ & $2.668(0.100)$ & $\underline{\mathrm{HML}_{t}}$ & $\underline{\text { Combined }}$ \\
& & $2.416(0.120)$ & $26.235(0.000)$ & $30.335(0.000)$ \\
Wald (p-value) & & $1.747(0.186)$ & $12.479(0.000)$ & $15.828(0.000)$ \\
\hline
\end{tabular}




\section{Table 4: GMM Estimation with Univariate Betas}

This table shows the results of GMM estimations using as test assets the 25 Fama-French size- and valuesorted portfolios and 10 distress portfolios with quarterly data from 1972:Q2 to 2008:Q4. The asset pricing restrictions are expressed in terms of univariate betas based on

$$
E\left[R_{t}\right]=\lambda_{0} \mathbf{1}_{N}+\lambda_{1} \frac{\operatorname{cov}\left(r_{t}, f_{1}\right)}{\sigma_{1}^{2}}+\cdots+\lambda_{k} \frac{\operatorname{cov}\left(r_{t}, f_{k}\right)}{\sigma_{k}^{2}}
$$

where $\sigma_{k}^{2}$ is the variance of the $k$ th factor, $\frac{\operatorname{cov}\left(R_{t}, f_{k}\right)}{\sigma_{k}^{2}}$ is the n-vector of coefficients from the univariate regression of $R_{t}$ on $f_{k}$, and $\lambda_{k}$ is the risk premium for $f_{k}$. The variables and testing methodology used are the same as described in Table 3 .

Private Investment Model

\begin{tabular}{|c|c|c|c|c|}
\hline Coefficient (t-stat) & $\frac{\text { CONSTANT }}{0.042(10.126)}$ & $-0.0 \frac{\mathrm{NCOR}_{t}}{49(-2.939)}$ & $\frac{E_{t}\left[\mathrm{NCOR}_{t+1}\right]}{-0.027(-5.075)}$ & $\frac{\mathrm{NCOR}_{t} \cdot E_{t}\left[\mathrm{NCOR}_{t+1}\right]}{0.002(4.466)}$ \\
\hline $\begin{array}{l}J(\mathrm{p} \text {-value }) \\
A d j R^{2}\end{array}$ & $\begin{array}{c}23.224(0.841) \\
0.688\end{array}$ & & & \\
\hline $\begin{array}{l}\Delta J(\mathrm{p} \text {-value }) \\
W \text { ald }(\mathrm{p} \text {-value })\end{array}$ & $\begin{array}{c}\frac{\mathrm{XMKT}_{t}}{13.574(0.000)} \\
9.997(0.002)\end{array}$ & $\begin{array}{c}\frac{\mathrm{SMB}_{t}}{2.985(0.084)} \\
1.504(0.220)\end{array}$ & $\begin{array}{c}\frac{\mathrm{HML}_{t}}{17.398(0.000)} \\
13.044(0.000)\end{array}$ & $\begin{array}{c}\text { Combined } \\
62.597(0.000) \\
23.427(0.000)\end{array}$ \\
\hline $\begin{array}{l}\Delta J(\mathrm{p} \text {-value }) \\
W \text { ald }(\mathrm{p} \text {-value })\end{array}$ & & $\begin{array}{c}\frac{\mathrm{INV}_{t}}{24.403(0.000)} \\
22.553(0.000)\end{array}$ & $\begin{array}{c}\frac{\mathrm{ROE}_{t}}{17.391(0.000)} \\
9.389(0.002)\end{array}$ & $\begin{array}{c}\frac{\text { Combined }}{35.510(0.000)} \\
26.286(0.000)\end{array}$ \\
\hline
\end{tabular}




\section{Table 5: Fama-MacBeth Regressions}

This table shows the results of Fama-MacBeth regressions using as test assets the 25 Fama-French size- and valuesorted portfolios and 10 distress portfolios with quarterly data from 1972:Q2 to 2008:Q4. The factor variables for the private investment model (CW, for Couch-Wu), Fama-French (FF), and Chen, Novy-Marx, and Zhang (CNZ) models are described in Table 3. We report two t-values for each parameter. The first one (in parentheses) is calculated using the uncorrected Fama-MacBeth standard errors, taken into account the serial correlation among pricing errors. The second one [in brackets] is calculated using Shanken's (1992) adjusted standard errors. For goodness of fit we report the adjusted $\mathrm{R}^{2}$ and Shanken's (1985) $T^{2}$ test which tests whether pricing errors in the cross sectional regression are all zero, with p-values in parentheses. The $T^{2}$ statistic follows a finite-sample $F$ distribution. We also use nested F-tests for comparing the marginal effect of adding one extra variable to the model or, in the case of "combined," the effect of adding all of the preceding variables in that row to the model. Panels A through C report results using the full sample whereas panels D through F report results excluding years 2007 and 2008 from the sample.

Panel A: Private Investment Model (All Years)

\begin{tabular}{|c|c|c|c|c|}
\hline $\begin{array}{l}\text { Coefficient } \\
\text { (t-stat) } \\
{[\text { Shanken } t]}\end{array}$ & $\begin{array}{c}\text { CONSTANT } \\
0.041 \\
(5.748) \\
{[3.146]}\end{array}$ & $\begin{array}{l}\frac{\mathrm{NCOR}_{t}}{-0.027} \\
(-1.354) \\
{[-0.758]}\end{array}$ & $\begin{array}{c}\frac{E_{t}\left[\mathrm{NCOR}_{t+1}\right]}{-0.023} \\
(-4.281) \\
{[-2.468]}\end{array}$ & $\begin{array}{c}\mathrm{NCOR}_{t} \cdot E_{t}\left[\mathrm{NCOR}_{t+1}\right] \\
0.001 \\
(1.393) \\
{[0.774]}\end{array}$ \\
\hline $\begin{array}{l}\operatorname{Adj} R^{2} \\
T^{2}\end{array}$ & $\begin{array}{c}0.698 \\
41.368(0.628)\end{array}$ & & & \\
\hline F-tests for FF & $\frac{\mathrm{XMKT}_{t}}{47.41(0.000)}$ & $\frac{\mathrm{SMB}_{t}}{3.06(0.090)}$ & $\frac{\mathrm{HML}_{t}}{30.52(0.000)}$ & $\frac{\text { Combined }}{17.44(0.000)}$ \\
\hline F-tests for CNZ & $\frac{\mathrm{XMKT}_{t}}{47.41(0.000)}$ & $\frac{\mathrm{INV}_{t}}{70.6 \overline{3(0.000)}}$ & $\frac{\mathrm{ROE}_{t}}{16.12(0.000)}$ & $\frac{\text { Combined }}{84.87(0.000)}$ \\
\hline
\end{tabular}

Panel B: Fama-French Model (All Years)

\begin{tabular}{|c|c|c|c|c|}
\hline $\begin{array}{l}\text { Coefficient } \\
\text { (t-stat) } \\
{[\text { Shanken } t]}\end{array}$ & $\begin{array}{c}\text { CONSTANT } \\
0.080 \\
(5.993) \\
{[4.505]}\end{array}$ & $\begin{array}{l}\frac{\mathrm{XMKT}_{t}}{-0.067} \\
(-4.527) \\
{[-3.596]}\end{array}$ & $\begin{array}{l}\frac{\mathrm{SMB}_{t}}{0.003} \\
(0.718) \\
{[0.702]} \\
\end{array}$ & $\begin{array}{c}\frac{\mathrm{HML}_{t}}{0.015} \\
(2.797) \\
{[2.716]} \\
\end{array}$ \\
\hline $\begin{array}{l}\operatorname{Adj} R^{2} \\
T^{2}\end{array}$ & $\begin{array}{c}0.793 \\
68.511(0.061)\end{array}$ & & & \\
\hline F-tests for CW & $\frac{\mathrm{NCOR}_{t}}{1.07(0.309)}$ & $\frac{E_{t}\left[\mathrm{NCOR}_{t+1}\right]}{36.54(0.000)}$ & $\frac{\mathrm{NCOR}_{t} \cdot E_{t}\left[\mathrm{NCOR}_{t+1}\right]}{8.30(0.007)}$ & $\frac{\text { Combined }}{11.94(0.000)}$ \\
\hline F-tests for CNZ & & $\frac{\mathrm{INV}_{t}}{11.94(0.002)}$ & $\frac{\mathrm{ROE}_{t}}{49.84(0.000)}$ & $\frac{\text { Combined }}{40.42(0.000)}$ \\
\hline
\end{tabular}

Panel C: Chen, Novy-Marx and Zhang Model (All Years)

\begin{tabular}{|c|c|c|c|c|}
\hline $\begin{array}{l}\text { Coefficient } \\
\text { (t-stat) } \\
\text { [Shanken t] }\end{array}$ & $\begin{array}{c}\text { CONSTANT } \\
-.011 \\
(-0.759) \\
{[-0.503]}\end{array}$ & $\begin{array}{c}\frac{\mathrm{XMKT}_{t}}{0.021} \\
(1.342) \\
{[0.950]} \\
\end{array}$ & $\begin{array}{c}\mathrm{INV}_{t} \\
0.028 \\
(4.316) \\
{[3.028]}\end{array}$ & $\begin{array}{c}\frac{\mathrm{ROE}_{t}}{0.037} \\
(4.442) \\
{[3.431]}\end{array}$ \\
\hline $\begin{array}{l}\operatorname{Adj} R^{2} \\
T^{2}\end{array}$ & $\begin{array}{c}0.834 \\
46.945(0.449)\end{array}$ & & & \\
\hline F-tests for CW & $26 . \frac{\mathrm{NCOR}_{t}}{45(0.000)}$ & $\frac{E_{t}\left[\mathrm{NCOR}_{t+1}\right]}{0.98(0.330)}$ & $\frac{\mathrm{NCOR}_{t} \cdot E_{t}\left[\mathrm{NCOR}_{t+1}\right]}{1.64(0.211)}$ & $\frac{\text { Combined }}{9.64(0.000)}$ \\
\hline F-tests for FF & & $20 . \frac{\mathrm{SMB}_{t}}{78(0.000)}$ & $\frac{\mathrm{HML}_{t}}{42.56(0.000)}$ & $\frac{\text { Combined }}{44.95(0.000)}$ \\
\hline
\end{tabular}


Panel D: Private Investment Model (Excluding 2007-08)

\begin{tabular}{|c|c|c|c|c|}
\hline $\begin{array}{l}\text { Coefficient } \\
\text { (t-stat) } \\
\text { [Shanken t] }\end{array}$ & $\begin{array}{c}\text { CONSTANT } \\
0.022 \\
(3.284) \\
{[1.809]}\end{array}$ & $\begin{array}{l}\frac{\mathrm{NCOR}_{t}}{-0.025} \\
(-1.177) \\
{[-0.663]}\end{array}$ & $\begin{array}{c}\frac{E_{t}\left[\mathrm{NCOR}_{t+1}\right]}{-0.018} \\
(-3.163) \\
{[-1.817]}\end{array}$ & $\begin{array}{c}\mathrm{NCOR}_{t} \cdot E_{t}\left[\mathrm{NCOR}_{t+1}\right] \\
0.001 \\
(1.027) \\
{[0.574]}\end{array}$ \\
\hline $\begin{array}{l}\text { Adj } R^{2} \\
T^{2}\end{array}$ & $\begin{array}{c}0.736 \\
43.907(0.572)\end{array}$ & & & \\
\hline F-tests for FF & $\frac{\mathrm{XMKT}_{t}}{7.75(0.009)}$ & $\frac{\mathrm{SMB}_{t}}{1.6 \frac{1(0.214)}{(1)}}$ & $\frac{\mathrm{HML}_{t}}{51.72(0.000)}$ & $\frac{\text { Combined }}{23.70(0.000)}$ \\
\hline F-tests for CNZ & $\frac{\mathrm{XMKT}_{t}}{7.75(0.009)}$ & $25.40 \frac{\mathrm{INV}_{t}}{(0.000)}$ & $9.6 \frac{\mathrm{ROE}_{t}}{(0.004)}$ & $\frac{\text { Combined }}{17.77(0.000)}$ \\
\hline
\end{tabular}

Panel E: Fama-French Model (Excluding 2007-08)

\begin{tabular}{|c|c|c|c|c|}
\hline $\begin{array}{l}\text { Coefficient } \\
\text { (t-stat) } \\
{[\text { Shanken } t]} \\
\end{array}$ & $\begin{array}{c}\text { CONSTANT } \\
0.075 \\
(5.221) \\
{[4.102]} \\
\end{array}$ & $\begin{array}{l}\frac{\mathrm{XMKT}_{t}}{-0.059} \\
(-3.719) \\
{[-3.053]}\end{array}$ & $\begin{array}{l}\frac{\mathrm{SMB}_{t}}{0.004} \\
(0.714) \\
{[0.701]} \\
\end{array}$ & $\begin{array}{l}\frac{\mathrm{HML}_{t}}{0.017} \\
(3.134) \\
{[3.061]} \\
\end{array}$ \\
\hline $\begin{array}{l}A d j R^{2} \\
T^{2}\end{array}$ & $\begin{array}{c}0.759 \\
80.126(0.020)\end{array}$ & & & \\
\hline F-tests for CW & $\frac{\mathrm{NCOR}_{t}}{0.74(0.396)}$ & $\frac{E_{t}\left[\mathrm{NCOR}_{t+1}\right]}{21.90(0.000)}$ & $\frac{\mathrm{NCOR}_{t} \cdot E_{t}\left[\mathrm{NCOR}_{t+1}\right]}{9.57(0.004)}$ & $\frac{\text { Combined }}{7.58(0.000)}$ \\
\hline F-tests for $\mathrm{CNZ}$ & & $9.6 \frac{\mathrm{INV}_{t}}{(0.004)}$ & $\frac{\mathrm{ROE}_{t}}{37.25(0.000)}$ & $\frac{\text { Combined }}{26.14(0.000)}$ \\
\hline
\end{tabular}

Panel F: Chen, Novy-Marx and Zhang Model (Excluding 2007-08)

\begin{tabular}{|c|c|c|c|c|}
\hline $\begin{array}{l}\text { Coefficient } \\
\text { (t-stat) } \\
\text { [Shanken t] }\end{array}$ & $\begin{array}{c}\text { CONSTANT } \\
-0.014 \\
(-0.913) \\
{[-0.560]}\end{array}$ & $\begin{array}{c}\frac{\mathrm{XMKT}_{t}}{0.028} \\
(1.656) \\
{[1.084]}\end{array}$ & $\begin{array}{c}\frac{\mathrm{INV}_{t}}{0.031} \\
(4.190) \\
{[2.685]}\end{array}$ & $\begin{array}{l}\frac{\mathrm{ROE}_{t}}{0.033} \\
(3.827) \\
{[2.822]}\end{array}$ \\
\hline $\begin{array}{l}\text { Adj } R^{2} \\
T^{2}\end{array}$ & $\begin{array}{c}0.832 \\
46.660(0.486)\end{array}$ & & & \\
\hline F-tests for CW & $10 \frac{\mathrm{NCOR}_{t}}{55(0.003)}$ & $\frac{E_{t}\left[\mathrm{NCOR}_{t+1}\right]}{0.76(0.391)}$ & $\frac{\mathrm{NCOR}_{t} \cdot E_{t}\left[\mathrm{NCOR}_{t+1}\right]}{0.40(0.530)}$ & $\frac{\text { Combined }}{3.96(0.018)}$ \\
\hline F-tests for FF & & $\frac{\mathrm{SMB}_{t}}{19.72(0.000)}$ & $\frac{\mathrm{HML}_{t}}{50.84(0.000)}$ & $\frac{\text { Combined }}{46.04(0.000)}$ \\
\hline
\end{tabular}




\section{Table 6: Comparison With Other Private Business Models}

This table shows the results of Fama-MacBeth regressions using as test assets the 25 Fama-French size- and value-sorted portfolios and 10 distress portfolios with quarterly data from 1972:Q2 to 2008:Q4 in the full sample for panels A and B, and data from 1972:Q2 to 2006:Q4 in panels C and D. The factor variables for the private investment model (CW, for Couch-Wu), Fama-French (FF), and Chen, Novy-Marx, and Zhang (CNZ) models are described in Table 3. For the Li, Vassalou, and Xing (2006) model, sectoral investment growth rates are as follows: $\mathrm{HHOLDS}_{t}$ is the household and nonprofit sector; $\mathrm{NFINCO}_{t}$ is the non-financial, non-farm sector; FINAN ${ }_{t}$ is the financial sector. For the Heaton and Lucas (2000) model, aggregate U.S. proprietary income growth is denoted by $\mathrm{PROP}_{t}$, aggregate U.S. employee compensation is denoted by $\mathrm{COMP}_{t}$, and the credit spread is denoted by $\mathrm{CRED}_{t}$. We report two t-values for each parameter. The first one (in parentheses) is calculated using the uncorrected Fama-MacBeth standard errors, taken into account the serial correlation among pricing errors. The second one [in brackets] is calculated using Shanken's (1992) adjusted standard errors. The last column reports the Shanken's (1985) $T^{2}$ test. It tests whether pricing errors in the cross sectional regression are all zero, with p-values (in parentheses). The $T^{2}$ statistic follows a finite-sample $F$ distribution.

Panel A: Li-Vassalou-Xing Model (Full Sample)

\begin{tabular}{lccccccc}
\hline & CONSTANT & HHOLDS $_{t}$ & NFINCO $_{t}$ & NCOR $_{t}$ & FINAN $_{t}$ & Adj $R^{2}$ & $T^{2}$ \\
\hline Coefficient & 0.015 & -0.038 & -0.063 & 0.030 & -0.033 & 0.424 & 37.453 \\
(t-stat) & $(2.206)$ & $(-3.005)$ & $(-4.002)$ & $(1.336)$ & $(-3.531)$ & & $(p=0.753)$ \\
[Shanken t] & {$[1.141]$} & {$[-1.619]$} & {$[-2.167]$} & {$[0.705]$} & {$[-1.920]$} & & \\
\hline
\end{tabular}

Panel B: Heaton-Lucas Model (Full Sample)

\begin{tabular}{lccccccc}
\hline & $\mathrm{CONSTANT}$ & $\mathrm{XMKT}_{t}$ & $\mathrm{PROP}_{t}$ & $\mathrm{COMP}_{t}$ & $\mathrm{CRED}_{t}$ & $\operatorname{Adj} R^{2}$ & $T^{2}$ \\
\hline Coefficient & 0.063 & -0.046 & -0.040 & -0.002 & 0.605 & 0.770 & 29.996 \\
(t-stat) & $(5.573)$ & $(-3.764)$ & $(-3.507)$ & $(-0.671)$ & $(3.524)$ & & $(p=0.926)$ \\
{$[$ Shanken t $]$} & {$[2.706]$} & {$[-2.134]$} & {$[-1.733]$} & {$[-0.338]$} & {$[1.745]$} & & \\
\hline
\end{tabular}

Panel C: Li-Vassalou-Xing Model (Excluding 2007-08)

\begin{tabular}{lccccccc}
\hline & $\mathrm{CONSTANT}$ & $\mathrm{HHOLDS}_{t}$ & $\mathrm{NFINCO}_{t}$ & $\mathrm{NCOR}_{t}$ & FINAN $_{t}$ & Adj $R^{2}$ & $T^{2}$ \\
\hline Coefficient & 0.012 & -0.027 & -0.057 & 0.041 & -0.031 & 0.322 & 40.391 \\
(t-stat) & $(1.798)$ & $(-2.269)$ & $(-3.753)$ & $(1.734)$ & $(-2.986)$ & & {$[p=0.686]$} \\
[Shanken t $]$ & {$[0.944]$} & {$[-1.241]$} & {$[-2.078]$} & {$[0.927]$} & {$[-1.632]$} & & \\
\hline
\end{tabular}

Panel D: Heaton-Lucas Model (Excluding 2007-08)

\begin{tabular}{lccccccc}
\hline & $\mathrm{CONSTANT}$ & $\mathrm{XMKT}_{t}$ & $\mathrm{PROP}_{t}$ & $\mathrm{COMP}_{t}$ & $\mathrm{CRED}_{t}$ & Adj $R^{2}$ & $T^{2}$ \\
\hline Coefficient & 0.052 & -0.032 & -0.042 & -0.0005 & 0.412 & 0.721 & 34.720 \\
(t-stat) & $(5.097)$ & $(-2.711)$ & $(-3.619)$ & $(-0.203)$ & $(2.645)$ & & {$[p=0.843]$} \\
[Shanken t $]$ & {$[2.605]$} & {$[-1.646]$} & {$[-1.883]$} & {$[-0.107]$} & {$[1.381]$} & & \\
\hline
\end{tabular}




\section{Table 7: Credit Crunch and Credit Boom Regressions}

This table reports private investment regressions conditional on credit boom and crunch periods, defined by whether the credit spread is high (above its mean in Panel A and its $75^{\text {th }}$ percentile in Panel B), or low (below its mean in Panel A and its $25^{t h}$ percentile in Panel B). The factor variables are defined as follows: NCOR $\mathrm{N}_{t}$ is the noncorporate investment growth rate in quarter $t ; E_{t}\left[\mathrm{NCOR}_{t+1}\right]$ is the forecasted private investment growth whose construction is described in Section 3.4 and Table $1 ; d_{B}$ is a credit boom dummy variable that equals one if the credit spread is below its mean (Panel A) or $25^{\text {th }}$ percentile (Panel B), and zero otherwise; $d_{C}$ is a credit crunch dummy variable that equals one if the credit spread is above its mean (Panel A) or $75^{t h}$ percentile (Panel B), and zero otherwise. The test assets are the 25 Fama-French size- and value-sorted portfolios plus 10 distress portfolios with quarterly data from 1972:Q2 to 2008:Q4. Panels A and B show the results of GMM estimation with multivariate betas using mean and quartile cut-offs, respectively. For the GMM criterion, we report the J-test of Hansen (1982) along with the corresponding p-value for the chi-square test of the overidentifying restrictions. The coefficients (risk premiums) during credit boom and crunch periods are tested under the null hypothesis of equality using the $\Delta J$ test of Newey and West (1987). Standard equality-of-coefficients tests are performed to see whether the variable estimates in credit boom and crunch periods are equal. The cross-sectional $A d j R^{2}$ is reported for the overall goodness of fit.

Panel A: GMM Estimation with Multivariate Betas (Mean Cut-Offs)

\begin{tabular}{lccccc}
\hline Coefficient (t-stat) & $\frac{\mathrm{CONSTANT}}{0.014(3.020)}$ & $-\frac{\mathrm{NCOR}_{t} \cdot d_{C}}{0.026(-2.510)}$ & $\frac{\mathrm{NCOR}_{t} \cdot d_{B}}{0.022(-2.532)}$ & $\frac{E_{t}\left[\mathrm{NCOR}_{t+1}\right] \cdot d_{C}}{-0.004(-1.205)}$ & $\frac{E_{t}\left[\mathrm{NCOR}_{t+1}\right] \cdot d_{B}}{-0.016(-2.783)}$ \\
\hline$J$ (p-value) & $21.109(0.884)$ & & \\
Adj $R^{2}$ & 0.541 & $\frac{E_{t}\left[\mathrm{NCOR}_{t+1}\right] \cdot d_{B}=E_{t}\left[\mathrm{NCOR}_{t+1}\right] \cdot d_{C}}{13.447(0.000)}$ \\
\hline$J(\mathrm{p}$-value) & $\frac{\mathrm{NCOR}_{t} \cdot d_{C}=\mathrm{NCOR}_{t} \cdot d_{B}}{5.770(0.016)}$ & \\
\hline
\end{tabular}

Panel B: GMM Estimation with Multivariate Betas (Quartile Cut-Offs)

\begin{tabular}{lccccc}
\hline & $\mathrm{CONSTANT}$ & $\frac{\mathrm{NCOR}_{t} \cdot d_{C}}{0.021(-2.23)}$ & $\frac{\mathrm{NCOR}_{t} \cdot d_{B}}{-0.007(-0.923)}$ & $\frac{E_{t}\left[\mathrm{NCOR}_{t+1}\right] \cdot d_{C}}{-0.009(-2.88)}$ & $\frac{E_{t}\left[\mathrm{NCOR}_{t+1}\right] \cdot d_{B}}{-0.015(-3.521)}$ \\
\hline$J$ Coefficient (t-stat) & $0.026(6.163)$ & $-0 . v a l u e)$ & $33.526(0.300)$ & & \\
$A d j R^{2}$ & 0.488 & $\frac{E_{t}\left[\mathrm{NCOR}_{t+1}\right] \cdot d_{B}=E_{t}\left[\mathrm{NCOR}_{t+1}\right] \cdot d_{C}}{9.121(0.003)}$ \\
\hline$J$ (p-value) & $\frac{\mathrm{NCOR}_{t} \cdot d_{C}=\mathrm{NCOR}_{t} \cdot d_{B}}{8.362(0.004)}$ & \\
\hline
\end{tabular}


Table 8: System Bootstrap Analysis

This table shows the results from a system bootstrap analysis, designed as follows. First, forecasted private investment growth $E_{t}\left[\mathrm{NCOR}_{t+1}\right]$ is estimated by an auxiliary regression as in Section 3.4 and Table 1 and residuals are saved. Second, factor loadings for 25 Fama-French size- and value-sorted portfolios and 10 distress portfolios are estimated from time-series regressions and residuals are saved. The OLS estimates are taken as given, that is, the null hypothesis is that the estimated model is correct. The auxiliary and time-series regressions are treated as a system and the residuals are bootstrapped in a manner that the contemporaneous relation is maintained. For each run, the bootstrapped residuals are added to the predicted values to create new depedent variables for the auxiliary and time-series regressions. Then, the auxiliary regression is re-estimated and its predicted value enters the time-series regressions. With the newly bootstrapped returns, a set of factor loadings are re-estimated for each asset and then risk premia and adjusted $R^{2}$ are estimated in the cross-sectional regression. The entire procedure is repeated 40,000 times. In this way, the small-sample distributions of the risk premia and adjusted $R^{2} \mathrm{~s}$ are generated. Panel A reports the distribution of the risk premia in our private investment model. The column Null contains the original OLS estimates from the Fama-MacBeth regressions. The percentile breakpoints are then reported, followed by the mean. The column $\hat{t}$ contains the bootstrapped t-statistics. Panel B reports the distribution of the cross-sectional adjusted $R^{2}$ for several models: our private investment model; Fama and French (1993); Chen, Novy-Marx and Zhang (2011); Li, Vassalou and Xing (2006); and Heaton and Lucas (2000).

Panel A: Risk Premia in Private Investment Model

\begin{tabular}{lcccccccc}
\hline & Null & 2.5 & 10 & 50 & 90 & 97.5 & Mean & $\hat{t}$ \\
\hline CONSTANT & 0.041 & 0.011 & 0.019 & 0.033 & 0.048 & 0.057 & 0.033 & 3.525 \\
NCOR $_{t}$ & -0.027 & -0.086 & -0.065 & -0.030 & 0.008 & 0.031 & -0.029 & -0.934 \\
$E_{t}\left[\mathrm{NCOR}_{t+1}\right]$ & -0.023 & -0.042 & -0.034 & -0.021 & -0.011 & -0.005 & -0.022 & -2.543 \\
$\mathrm{NCOR}_{t} \cdot E_{t}\left[\mathrm{NCOR}_{t+1}\right]$ & 0.001 & -0.002 & -0.001 & 0.000 & 0.002 & 0.003 & 0.000 & 0.829 \\
\hline
\end{tabular}

Panel B: Adjusted $R^{2}$ across All Models

\begin{tabular}{lccccccc}
\hline & Null & 2.5 & 10 & 50 & 90 & 97.5 & Mean \\
\hline Private Investment (Couch \& Wu) & 0.698 & 0.140 & 0.303 & 0.577 & 0.750 & 0.812 & 0.549 \\
Fama \& French & 0.793 & 0.521 & 0.599 & 0.716 & 0.801 & 0.838 & 0.706 \\
Chen, Novy-Marx, \& Zhang & 0.834 & 0.414 & 0.560 & 0.752 & 0.854 & 0.885 & 0.726 \\
Li, Vassalou, \& Xing & 0.424 & 0.073 & 0.226 & 0.513 & 0.705 & 0.773 & 0.487 \\
Heaton \& Lucas & 0.770 & 0.293 & 0.444 & 0.668 & 0.803 & 0.849 & 0.642 \\
\hline
\end{tabular}




\section{Table 9: Independent Bootstrap Analysis}

This table shows the results from an independent bootstrap analysis, by the similar methodology as in Table 8 with the following exception. The auxiliary regression is treated independently from the time-series regressions. Residuals are bootstrapped independently, so the contemporaneous relation is not maintained. The bootstrap analysis generates small-sample distributions of risk premia and cross-sectional adjusted $R^{2}$ s. The column Null contains the original OLS estimates from the Fama-MacBeth regressions. The percentile breakpoints are reported, followed by the mean. The column $\hat{t}$ contains the bootstrapped t-statistics.

Private Investment Model

\begin{tabular}{lcccccccc}
\hline & Null & 2.5 & 10 & 50 & 90 & 97.5 & Mean & $\hat{t}$ \\
\hline CONSTANT $_{\text {NCOR }}$ & 0.041 & 0.009 & 0.018 & 0.033 & 0.049 & 0.058 & 0.033 & 3.402 \\
$E_{t}\left[\mathrm{NCOR}_{t+1}\right]$ & -0.027 & -0.088 & -0.068 & -0.031 & 0.009 & 0.031 & -0.031 & -0.896 \\
$\mathrm{NCOR}_{t} \cdot E_{t}\left[\mathrm{NCOR}_{t+1}\right]$ & -0.023 & -0.043 & -0.035 & -0.021 & -0.011 & -0.005 & -0.022 & -2.455 \\
\hline $\operatorname{Adj} R^{2}$ & 0.001 & -0.002 & -0.001 & 0.000 & 0.002 & 0.003 & 0.000 & 0.866 \\
\hline
\end{tabular}


Figure 1: Noncorporate Investment Growth, Realized and Forecasted

(a) NCOR (1972:Q3-2009:Q1)

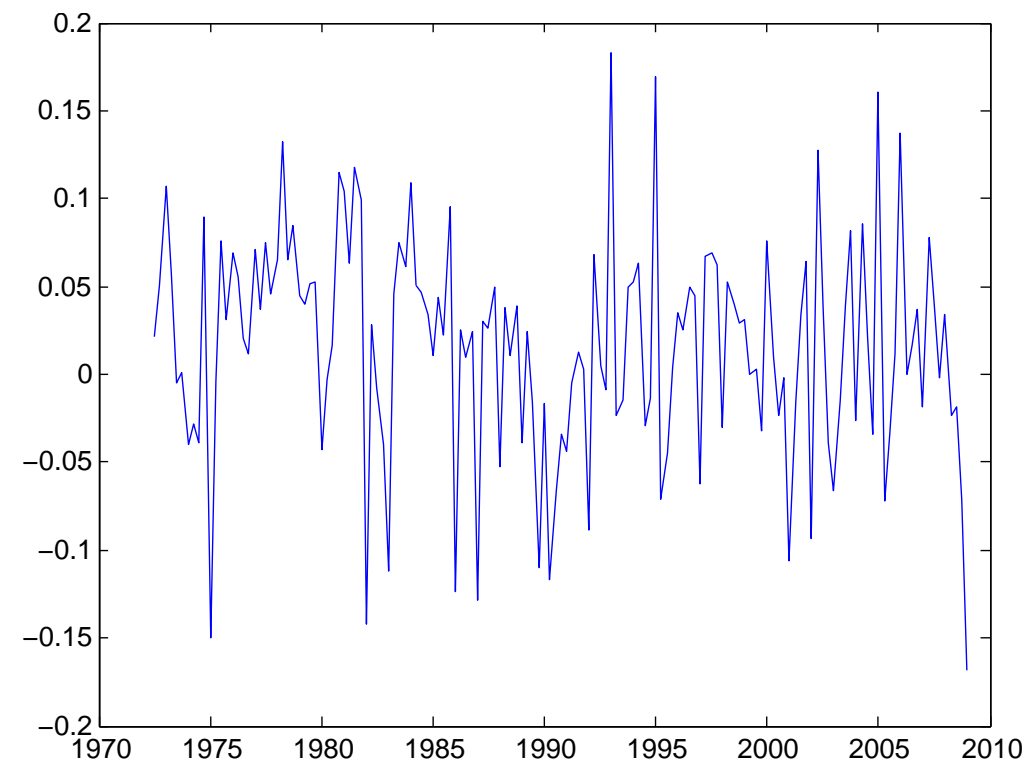

(b) $E_{t}\left[\mathrm{NCOR}_{t+1}\right](1972: \mathrm{Q} 2-2008: \mathrm{Q} 4)$

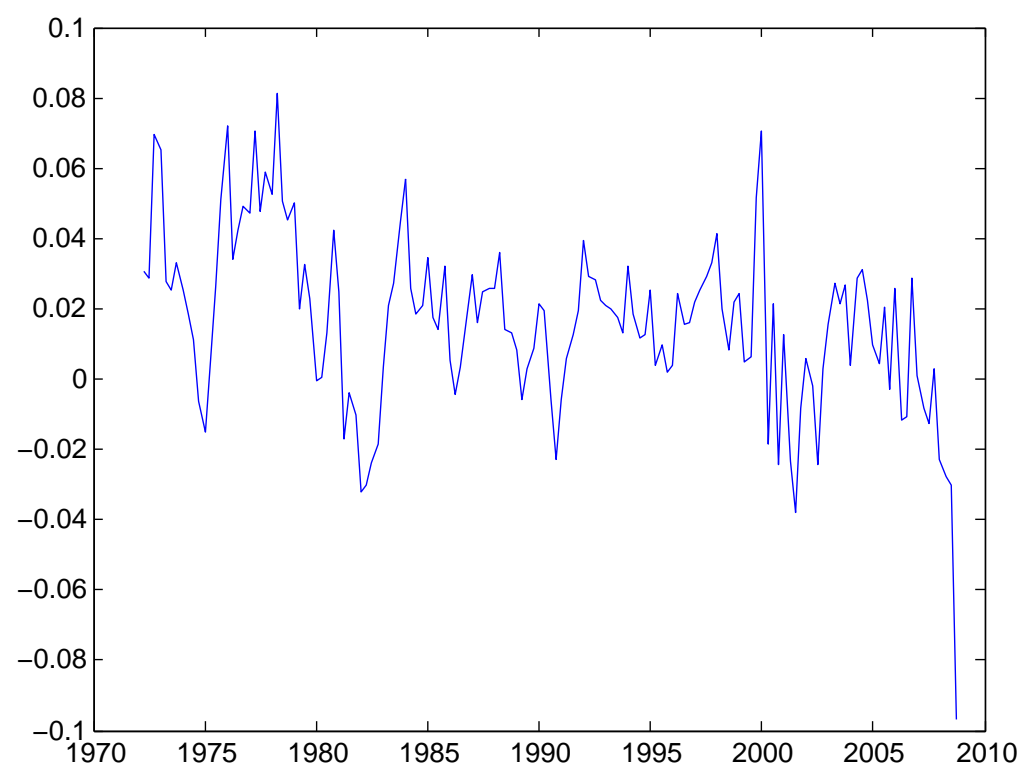









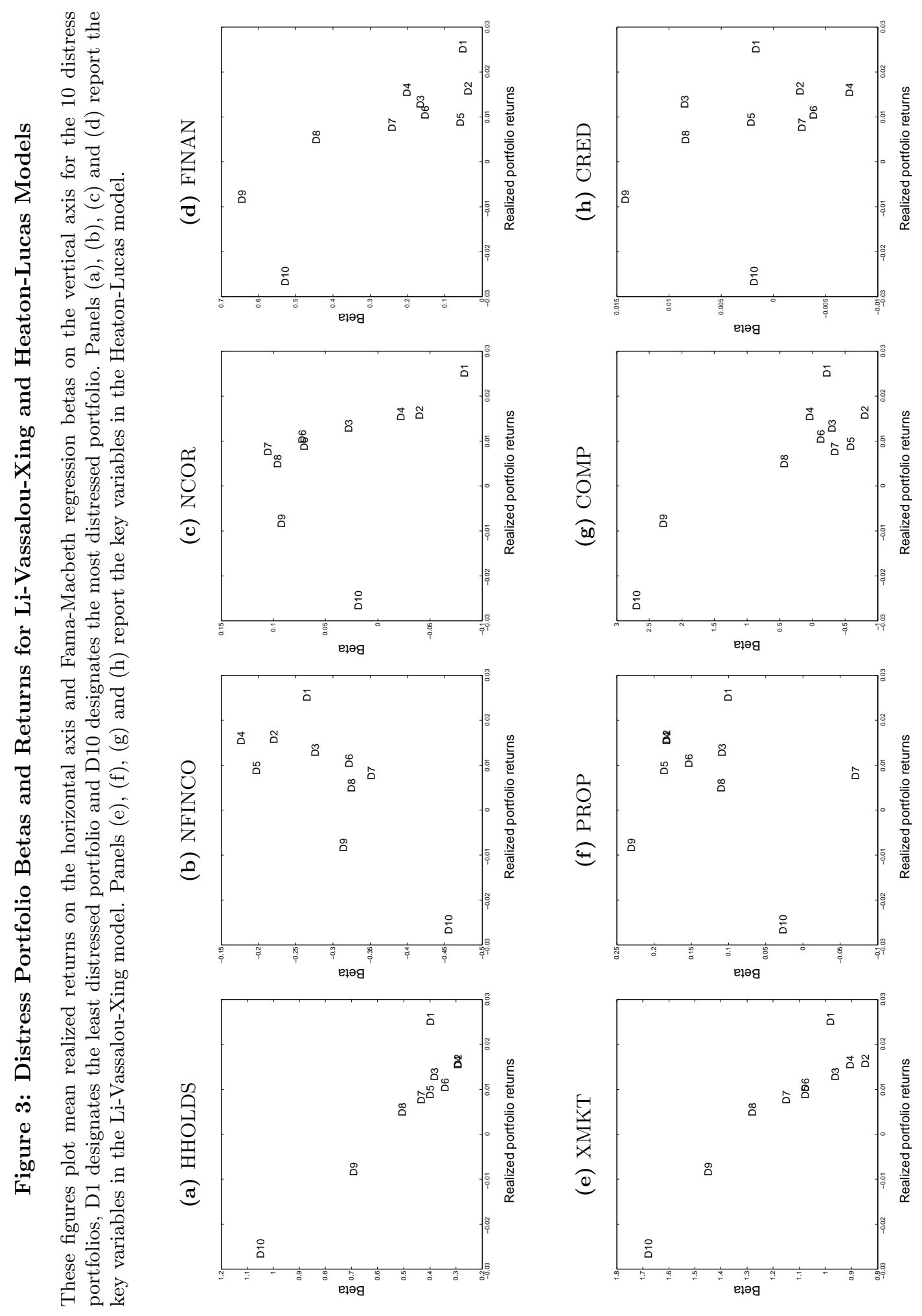

